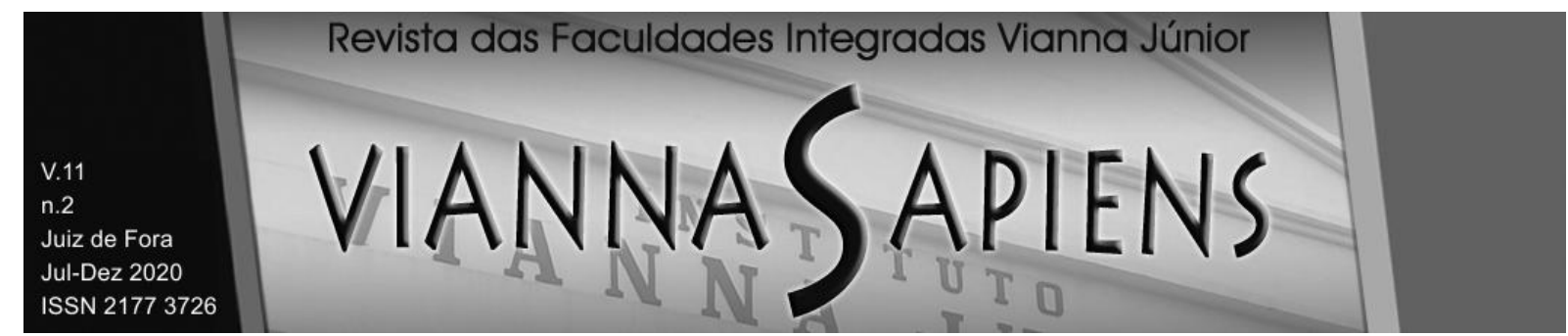

\title{
Proposta de gestão e dimensionamento de estoques em uma mercearia de pequeno porte
}

DOI: 10.31994/rvs.v11i2.657

Jaíny Chaves Carrijo ${ }^{1}$

Tatielle Menolli Longhini ${ }^{2}$

\section{RESUMO}

As organizações varejistas precisam gerenciar o estoque para dispor do produto certo, na hora e na quantidade certas aos seus clientes. Nesse sentido, o presente estudo visa propor a gestão e dimensionamento de estoques para uma mercearia de pequeno porte, através da priorização dos itens de demanda constante mais lucrativos, utilizando a ferramenta da Curva $A B C$, e nos cálculos de índice de desempenho de estoques, como estoque de segurança, estoque máximo, ponto e tempo de reposição, e lote econômico de compras. A proposta foi baseada nos índices calculados, os quais sugeriram uma redução do número de pedidos e um lote de compras maior, de modo a possibilitar uma redução de custos e tornar a estocagem viável economicamente.

\section{PALAVRAS-CHAVE: CURVA ABC. LOTE ECONÔMICO DE COMPRAS. MICRO E PEQUENAS EMPRESAS. GESTÃO DE ESTOQUES.}

\footnotetext{
${ }^{1}$ Graduada em Engenharia de Produção pelo Instituto Federal de Minas Gerais campus Governador Valadares (IFMG-GV), E-mail: jainycarrijo@hotmail.com, ORCID ID 0000-0001-9988-2776.

${ }^{2}$ Mestre em Administração pela Universidade Federal de Minas Gerais (UFMG), Professora do curso de Engenharia de Produção pelo Instituto Federal de Minas Gerais campus Governador Valadares (IFMG-GV), E-mail: tatielle.longhini@ifmg.edu.br, ORCID ID 0000-0002-2934-9893.
} 


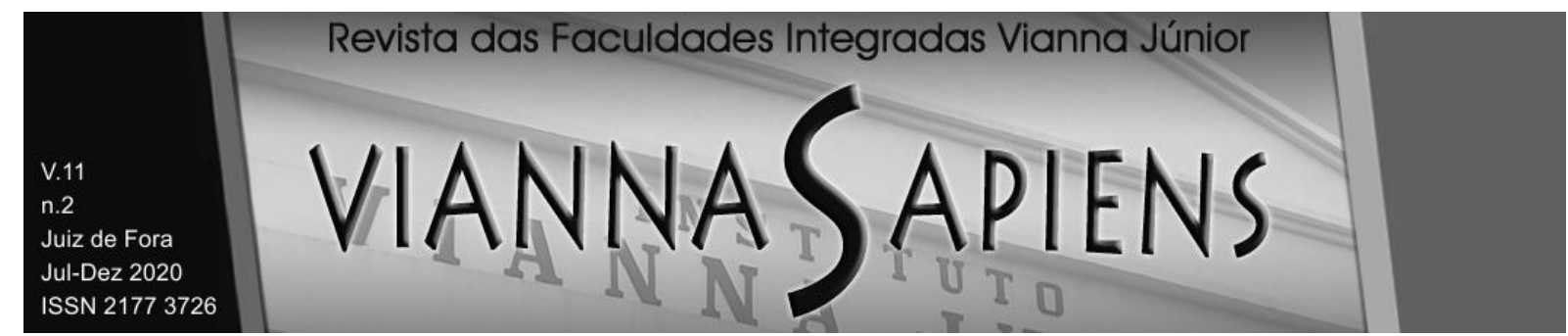

Inventory management and sizing proposal in a small grocery store

\begin{abstract}
Retail organizations need to manage inventory to have the right product at the right time and in the right quantity for their customers. In this sense, the present study aims to propose inventory management and sizing for a small grocery store, by prioritizing the most profitable items in constant demand, using the ABC Curve tool, and in the stock performance index calculations, as safety stock, maximum stock, point and replacement time, and economical lot of purchases. The proposal was based on the calculated indices, which suggested a reduction in the number of orders and a larger purchase lot, in order to enable cost reduction and make storage economically viable.
\end{abstract}

KEY-WORDS: ABC CURVE. ECONOMICAL LOT OF PURCHASES. MICRO AND SMALL BUSINESSES. INVENTORY MANAGEMENT.

\title{
INTRODUÇÃO
}

Diante do atual cenário, é fundamental que as empresas visem ações e estratégias para aumento de competitividade. É comum notar que uma parcela, principalmente as de pequeno porte, enfrenta problemas devido à falta de gestão de seus estoques. Sobre isso, pode-se citar o excesso de materiais que, além de ocupar uma área maior no local de armazenamento, corre o risco de obsolescência e de desperdício (VENANZI, SILVA, 2013).

Grande parte das empresas de pequeno porte, afirmam Ferreira et al (2011), possuem dificuldades de gerenciamento. Isso se deve à ausência de um sistema de 


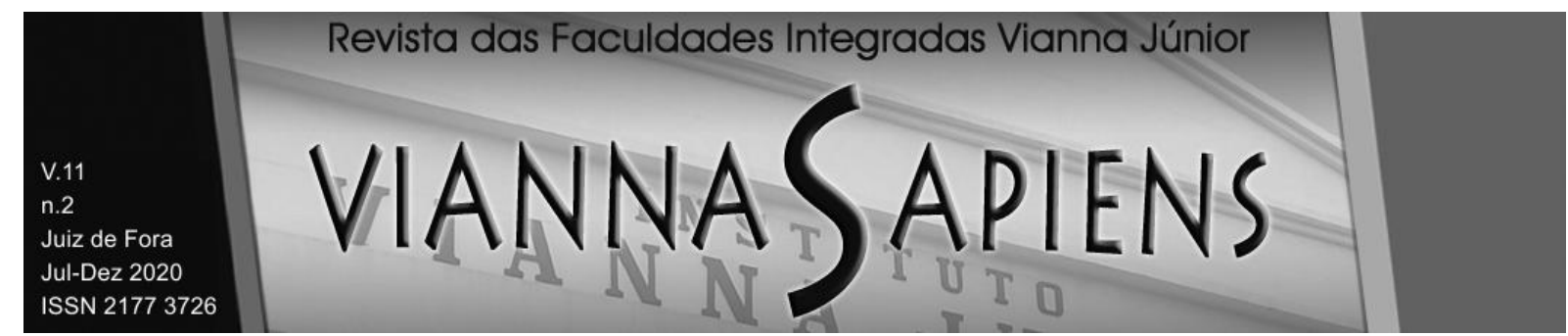

gestão de estoque, o que pode dificultar o controle e consequentemente, comprometer sua lucratividade e a capacidade de venda (CHIAVENATO, 2005).

Para isso, é também importante priorizar itens em estoque, de modo a otimizar sua gestão (FRANCISCHINI; GURGEL, 2002). Uma das ferramentas usadas com tal finalidade é a Curva ABC (LETTI; GOMES, 2014; CARVALHO, 2018; SANTANA, 2014).

Em estudo publicado pela Confederação Nacional do Comércio de Bens, Serviços e Turismo, Everton Junior (2017) relata que a maioria das micro e pequenas empresas (MPEs) são de base familiar, sendo que o proprietário geralmente é o gestor e as decisões transparecem sua percepção subjetiva. Porém, este é um fato que precisa ser acompanhado, pois, para definir ações estratégicas, é necessário calcular e avaliar variáveis do processo para tomar decisões racionais (TADEU, 2010).

Paralelamente, o setor de comércio varejista vem se destacando entre as empresas de pequeno porte. No ano de 2015, registrou-se um crescimento do número de MPEs, sendo 6,8 milhões em atividade, dos quais 3,1 milhões são pertencentes ao setor de comércio (SEBRAE, 2017). Entretanto, empresas deste ramo ofertam uma grande variedade de itens, o que pode dificultar o gerenciamento de seu estoque (KOTLER, 1998).

O presente trabalho tem como foco uma mercearia varejista, que não faz uso de um sistema informatizado para monitoramento de dados do estoque. Tal controle é realizado pelo proprietário por anotações manuais que, dadas as imprecisões de registro, não apresentam a situação real da empresa. Com isso, este estudo busca responder à seguinte questão: "De que maneira a gestão e dimensionamento de estoques pode contribuir para o controle de ressuprimento de mercadorias em uma empresa de pequeno porte?".

Sendo assim, tem-se como objetivo propor um sistema de gestão e dimensionamento de estoques em uma mercearia de pequeno porte. Para isso, buscou-se descrever 0 atual processo de controle, consolidar dados de 


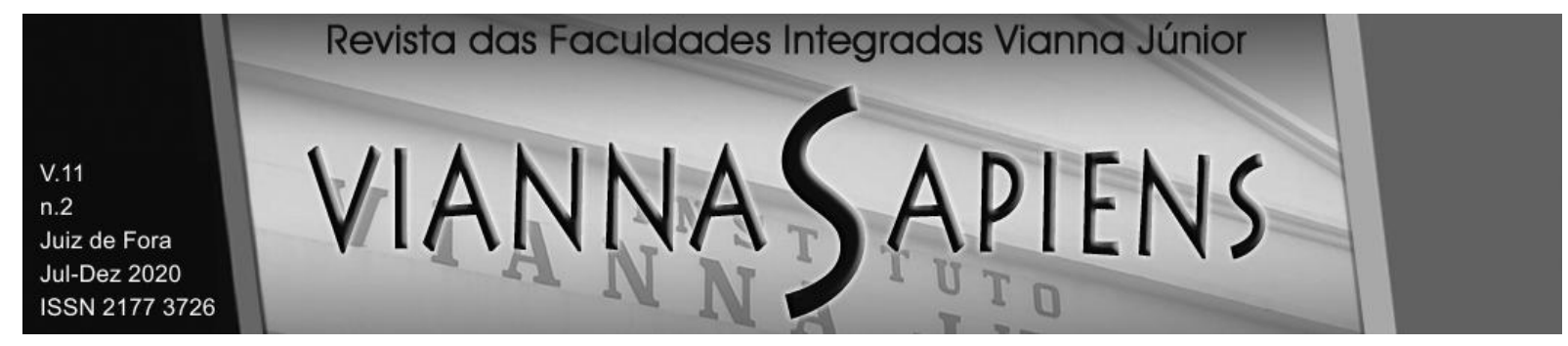

ressuprimento e de demanda de itens, priorizar itens de demanda constante com maior relevância em termo de lucro e, então, aplicar técnicas de dimensionamento para manutenção estoques.

A seguir, será apresentado o embasamento teórico usado para o estudo e, posteriormente, a metodologia da pesquisa e o resultado do estudo de caso, com a aplicação da ferramenta Curva $A B C$ e dos índices de desempenho de estoque. Por fim, será exibida a proposta de melhoria sugerida à empresa.

\section{GESTÃO E DIMENSIONAMENTO DE ESTOQUES}

O estoque é indispensável aos varejistas, pois é necessário dispor para vendê-los no momento de solicitação dos clientes (BAILY et al, 2000). Por isso, há o armazenamento de itens (matérias-primas ou produtos acabados), em dada quantidade, durante algum período de tempo até o seu despacho (MOREIRA, 2002; CHIAVENATO, 2005).

É fundamental que os estoques sejam controlados adequadamente. Para isso, procede-se o seu gerenciamento, com o qual é possível monitorar os produtos, obtendo análises sobre qualidade, aquisição, armazenamento e uso dos materiais, o que reflete na decisão de periodicidade e quantidade de compra (SILVA, 1981; VENANZI; SILVA, 2013; MONKS, 1987).

Através dos sistemas de controle de estoques, de acordo com Slack et al. (2009), são gerados pedidos, atualizados os registros de estoques e previstas as demandas de consumo. Assim, há maior precisão de informações (POZO, 2010).

A gestão de estoques deve conciliar as atividades dos setores de compras, produção, vendas e financeiro (VENANZI; SILVA, 2013). Uma das primeiras análises a ser considerada no estoque é a relação entre consumo e reposição, que é estabelecida em função da quantidade consumida ao longo do tempo. Por isso, são 


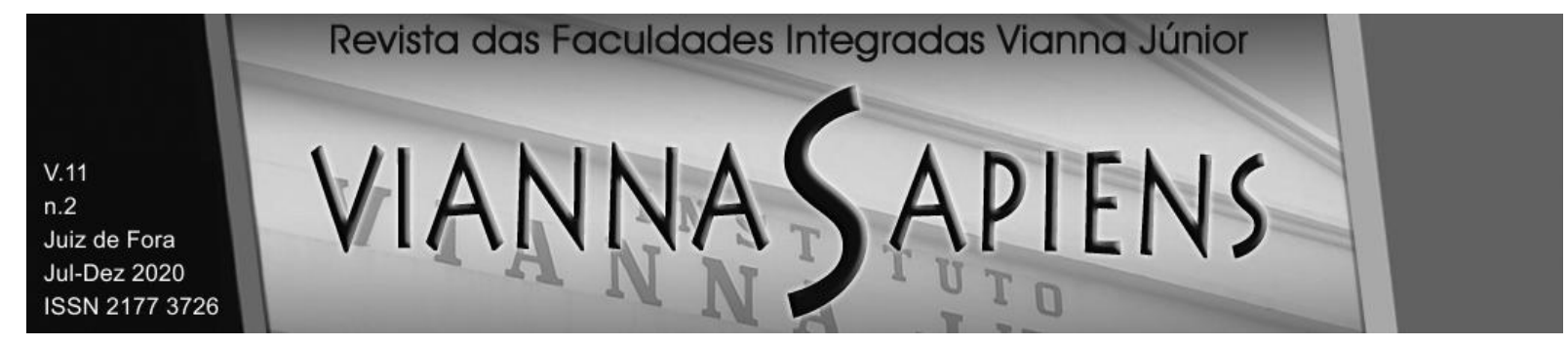

calculados o Consumo Médio (CM), o Estoque de Segurança (ES), o Ponto de Reposição (PR), o Lote Econômico de Compra (LEC) e o Estoque Máximo ( $E_{\text {máx }}$ ).

O consumo médio (CM) se refere à média das retiradas do estoque, ou seja, das vendas de cada item (VENANZI; SILVA, 2013). Para o presente estudo, o CM será referente a quantidade média de itens vendidos no mês, conforme a Equação 1.

$$
C M=\frac{C 1+C 2+C 3+\cdots+C n}{n}
$$

Onde:

CM: Consumo médio

Cn: Consumo do período/mês $n$

$\mathrm{n}$ : Quantidade de períodos/meses

Outro índice importante é o estoque de segurança (ES), conhecido também como estoque de reserva. Consiste na quantidade mínima de itens que devem existir em estoque para não parar as atividades operacionais, funcionando como pulmão contra as variações de demanda e de suprimento (LOPRETE et al., 2009; POZO, 2010). Uma das fórmulas para se calcular o estoque mínimo, de acordo com Pozo (2010), é apresentada da Equação 2, dada pela média de consumo do item em determinado período e baseado em coeficiente de risco.

$$
E S=\delta x k
$$

Onde:

$\delta$ : Desvio padrão da demanda

$k$ : Coeficiente de risco 


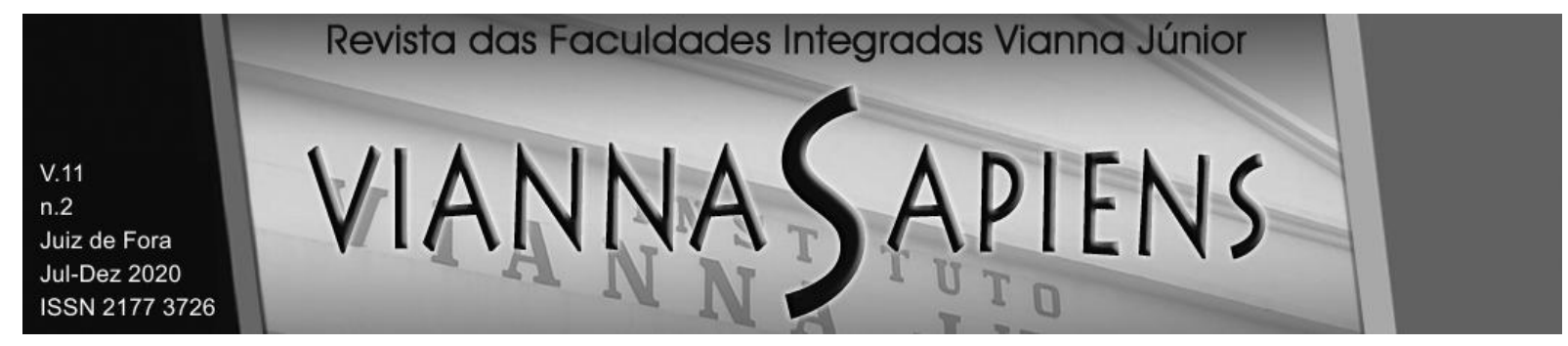

Já o coeficiente de grau de risco ( $k$ ) é determinado conforme um grau de atendimento que se deseja atingir. Essa relação é apresentada, conforme Pozo (2010), na Tabela 1.

Tabela 1 - Valores do coeficiente $\boldsymbol{k}$ para graus de atendimento com riscos $\%$.

\begin{tabular}{cc|cc|cc}
\hline Risco \% & $K$ & Risco $\%$ & $K$ & Risco \% & $k$ \\
\hline 52,00 & 0,102 & 80,00 & 0,842 & 90,00 & 1,282 \\
55,00 & 0,126 & 85,00 & 1,036 & 95,00 & 1,645 \\
60,00 & 0,253 & 86,00 & 1,085 & 97,50 & 1,960 \\
65,00 & 0,385 & 87,00 & 1,134 & 98,00 & 2,082 \\
70,00 & 0,524 & 87,50 & 1,159 & 99,00 & 2,326 \\
75,00 & 0,674 & 88,00 & 1,184 & 99,50 & 2,576 \\
78,00 & 0,775 & 89,00 & 1,233 & 99,90 & 3,090 \\
\hline
\end{tabular}

Fonte: Pozo (2010).

O ponto reposição (PR), ou ponto de pedido, indica quando se deve comprar o material. O PR é dado em unidades e, segundo Corrêa e Corrêa (2012), é a quantidade que aponta a necessidade de um novo pedido de compras. Segundo Venanzi e Silva (2013), PR pode ser calculado através da relação a seguir:

$$
P R=(C M \times T R)+E S
$$

Onde:

$P R$ : Ponto de reposição

$C M$ : Consumo médio mensal

TR: Tempo de reposição

ES: Estoque de segurança

O estoque de segurança é adicionado ao ponto de reposição como prevenção para que não falte o material durante o tempo de espera (LUSTOSA et al, 2008). Logo, quando acontecer do fornecedor atrasar a entrega da compra, o estoque de segurança servirá como uma reserva para que não chegue a nível zero.

Já o tempo de reposição (TR) é o lead time do ressuprimento (CORRÊA et al, 2013). Ou seja, é o tempo decorrido entre o pedido e a chegada efetiva do mesmo 


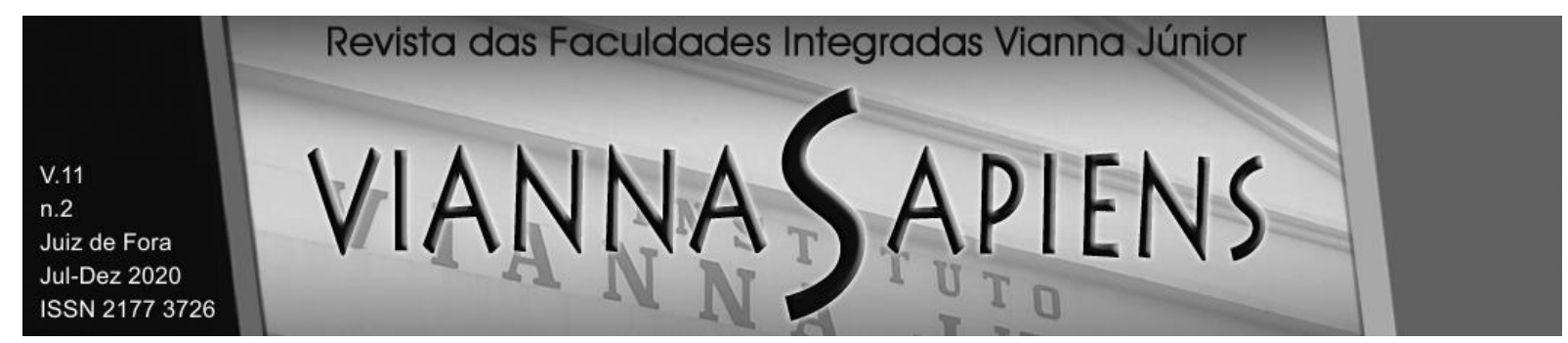

ao estoque. Para isso, considera o tempo de emissão, de preparação do pedido, o tempo de transporte e de inspeção dos itens, e deve ser dado na mesma unidade do consumo médio. A Figura 1 mostra a relação entre o PR, TR, ES, bem como o lote de compras e o estoque máximo que serão explicados posteriormente.

\section{Figura 1 - Relação entre os índices de desempenho de estoque.}

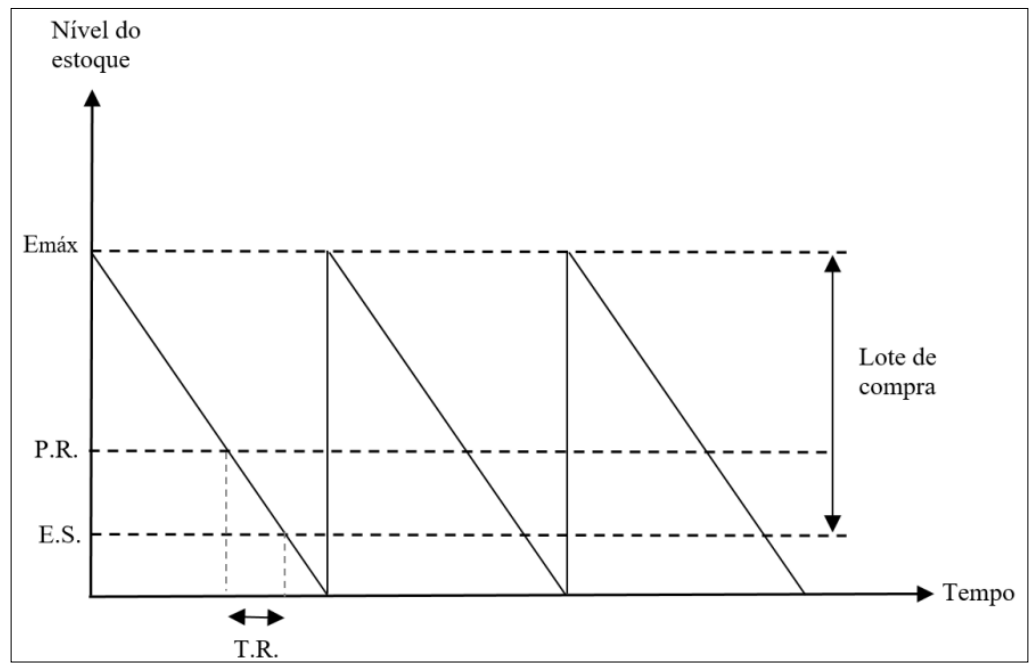

Fonte: Corrêa e Corrêa (2012).

O lote econômico de compra (LEC) representa a quantidade de pedido ideal para cada item, equilibrando vantagens e desvantagens de se manter estoque (SLACK et al, 2009). O LEC busca balancear os custos de armazenagem (proporcional à quantidade), com o custo de pedido (inversamente proporcional à quantidade), de modo a minimizar o custo total (PLOSSL, 1985; DIAS, 1993).

Existem diversas maneiras de se calcular o LEC, a depender dos custos que são considerados. Para o presente estudo, foi assumido o custo de cada pedido e o custo de estocagem, conforme indicado por Peinado e Graeml (2007).

O custo do pedido é o custo obtido para gerar um pedido. Segundo Tubino (2009) e Peinado e Graeml (2007), ele é composto pelos custos diretos administrativos, de mão de obra para processamento e emissão do pedido e/ou da ordem de compra - e pelos indiretos, como luz, telefone, aluguel e transporte. 


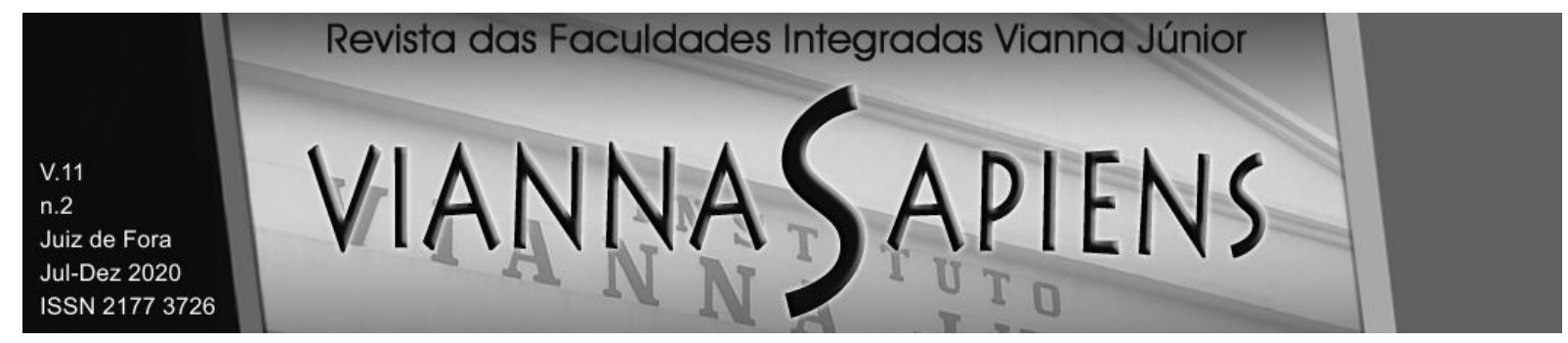

Outro custo considerado no LEC é o custo de estocagem (CE), associado à armazenagem dos materiais e que considera taxa de juros, ou custo de oportunidade. Segundo Samanez (2009), o custo de oportunidade indica o custo relacionado à uma oportunidade renunciada (ou, uma renda maior em um investimento alternativo).

Igualando as equações, do custo de pedido com o custo de estocagem, é possível encontrar o lote de compras ideal que equilibre os custos de pedido e de estocagem, de modo que se defina a quantidade que minimize os custos. O LEC é definido pela Equação 4, conforme proposto por Peinado e Graeml (2007).

$$
L E C=\sqrt{\frac{2 * D * C p}{t * C u}}
$$

Onde:

LEC: Lote econômico de compra

$D$ : Demanda no período

Cp: Custo unitário do pedido

$t$ : taxa de juros ou custo de oportunidade

Cu: Custo unitário do material

Para o cálculo correto do $L E C$, é necessário que os indicadores sejam referentes ao mesmo período de tempo, de modo a não haver distorções no resultado. Para o presente estudo, serão consideradas a demanda anual e custo de oportunidade também anual.

O cálculo do $L E C$ apresenta algumas restrições/premissas que precisam ser consideradas para efetivação do modelo. Sabe-se que o custo de pedido independe do tamanho do lote e o custo unitário do item também independe da quantidade comprada no lote (PEINADO, GRAEML, 2007). Além disso, o material ou produto analisado é único e as demanda dos itens são constantes e lineares ao longo do período e o tempo de entrega dos produtos não varia. 


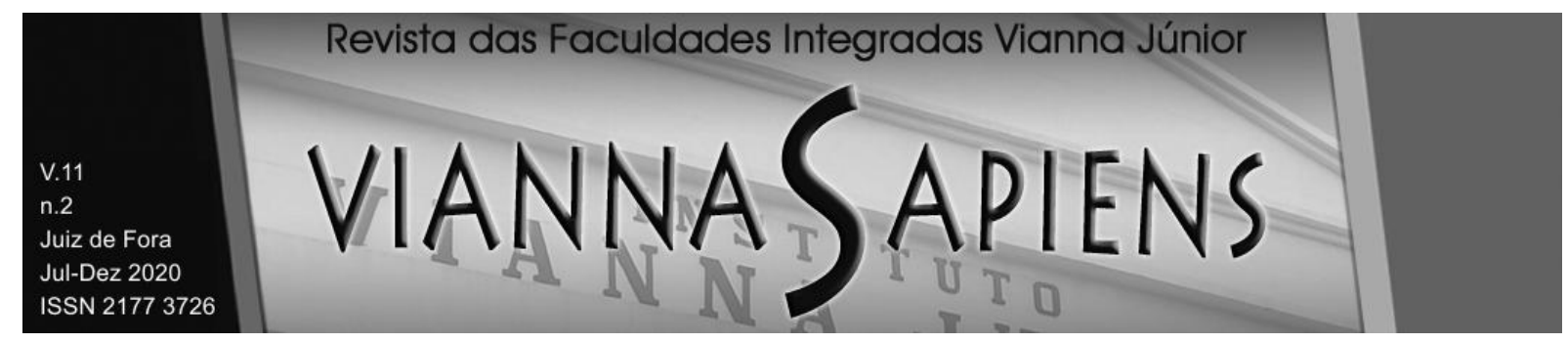

Por fim, o estoque máximo $\left(\mathrm{E}_{\text {Máx }}\right)$ corresponde à quantidade máxima de estoque planejado e permitido para determinado item. Tófoli (2012) define como sendo a soma do lote de compras com o estoque de segurança (Equação 5).

$$
E_{\text {Máx }}=L C+E S
$$

Onde:

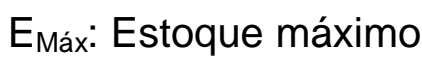

LC: Lote de compra

ES: Estoque de segurança

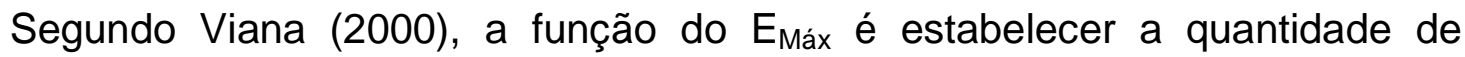
ressuprimento, analisando o estoque virtual, logo quando o pedido é feito

\section{CURVA ABC}

Uma das ferramentas mais utilizadas na gestão de estoque é a Curva $A B C$. Também conhecida como lei $80 / 20$, com ela é possível perceber que $20 \%$ dos produtos (causas) são responsáveis por aproximadamente $80 \%$ do lucro da empresa (efeitos) (PEINADO; GRAEML, 2007). Segundo Carvalho (2002), trata-se de um método que permite priorizar decisões com base nos itens que são mais importantes - ou seja, os que causam maior impacto.

Pinto (2002), Corrêa et al (2013), Luchezzi (2015) e Chiavenato (2005) afirmam que a curva $A B C$ pode ser aplicada para classificar itens em 3 grupos, de acordo com seu valor total de uso e por grau de importância em função de um valor financeiro. São eles:

a) Classe A: $15 \%$ a $20 \%$ dos itens que representam cerca de $80 \%$ do valor do estoque;

b) Classe B: $30 \%$ a $40 \%$ dos itens que representam cerca de $15 \%$ do valor do estoque; 


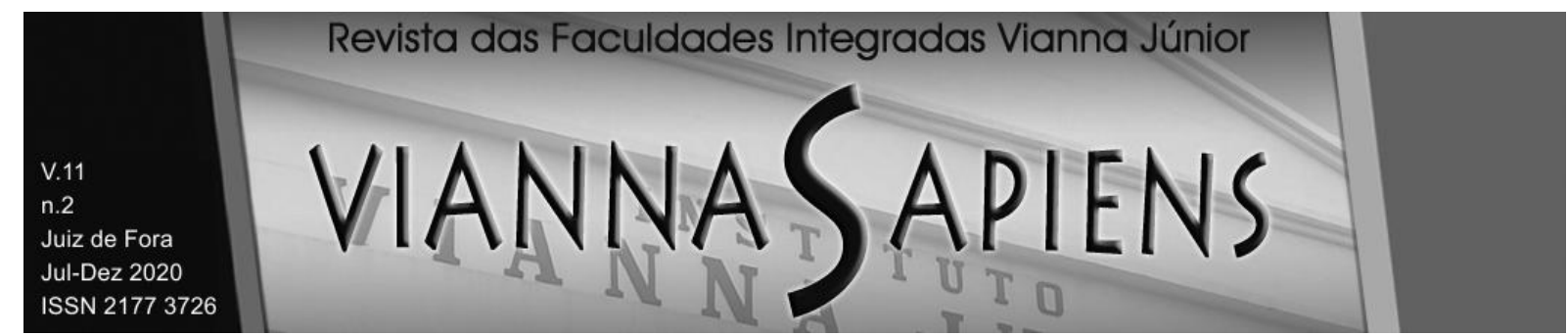

c) Classe C: $40 \%$ a $50 \%$ dos itens que representam cerca de $5 \%$ a $10 \%$ do valor total do estoque;

Os itens classe A são considerados os mais importantes devido sua alta representatividade em valor monetário. Na classe $B$ estão os itens intermediários e a classe C corresponde a uma grande parte dos itens, mas que são considerados menos importantes, já que representam pequena parcela no valor total do estoque.

Após classificados os itens, é possível, então, estabelecer o grau de importância que a gestão deve dedicar a cada uma das classes. As informações obtidas através da aplicação e análise da curva ABC são de grande relevância para que a gerência planeje e gerencie seu estoque, além de gerar informações que baseiem a tomada de decisão da empresa.

\section{MERCADO DE PEQUENAS EMPRESAS E SUAS DIFICULDADES}

As micro e pequenas empresas do setor de comércio e serviço são classificadas, segundo o SEBRAE (2018), como empresas que possuem até 9 funcionários, com faturamento bruto anual de até $R \$ 360.000,000$. Estes pequenos negócios continuam crescendo no Brasil.

Segundo estudos realizados pelo SEBRAE (2017), das 6.775.493 MPEs já existentes no Brasil no ano de 2015, praticamente a metade se encontrava na região Sudeste do país, sendo que Minas Gerais já possuía 743.391 MPEs, considerando indústria, comércio, construção e serviços. Trata-se do segundo estado da região Sudeste com o maior número de MPEs, perdendo apenas para o estado de São Paulo que representa, sozinho, cerca de $10,97 \%$ do total.

Em seu estudo sobre a sobrevivência das empresas, o SEBRAE (2016) aponta as principais dificuldades enfrentadas pelas microempresas em seu primeiro ano de atividade, tais como falta de clientes, de capital, de investimento, de mão de obra e de planejamento. Associa-se a isso a incidência de impostos/tributos, a 


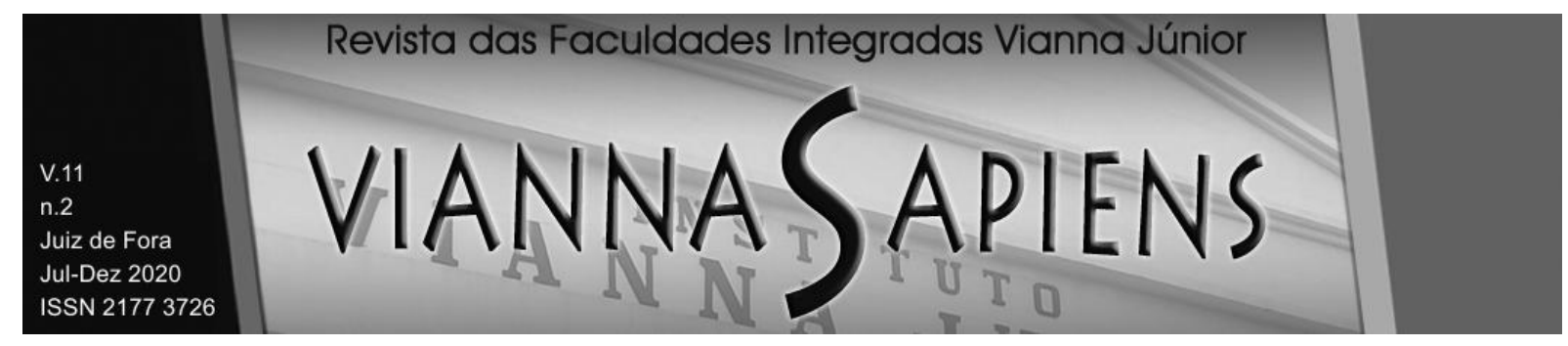

inadimplência, a concorrência e falta de capacitação em funções administrativas. Zimmerer e Scarborough (1994) citam, ainda, fatores como pouca experiência, falta de controle financeiro adequado, além de questões como expansão não planejada, falhas no planejamento e falta de controle de estoque.

A tecnologia de informação também é apontada, no estudo de Moraes (2005), como uma dificuldade para as pequenas empresas, pois existe uma resistência ao uso. Apesar do crescimento da inserção de softwares, eles não são usados como ferramenta auxiliar para a tomada de decisão.

Diante das diversas dificuldades apresentadas pelos autores, é essencial que as MPEs inovem sua forma de gestão para superarem as dificuldades enfrentadas. Para isso, devem promover ações de gestão e controle de modo a aumentar sua qualidade como um todo e, principalmente, o seu potencial competitivo.

\section{METODOLOGIA}

O presente estudo se classifica como pesquisa aplicada, pois visa adquirir conhecimentos para uma aplicação prática, através de resultados que gerem algum tipo de melhoria ou solução de problemas para o estoque da empresa (BOISSEL, 2004). Possui caráter quantitativo devido à sua objetividade, já que recorre a análises matemáticas para entender as variáveis e descrever o motivo do fenômeno em estudo (SILVEIRA; CÓRDOVA, 2012). Também possui caráter qualitativo pois busca analisar profundamente a natureza dos fenômenos estudados, compreendendo e explicando-os, analisando a relação entre particularidades do problema (RICHARDSON, 1999).

É considerada, quanto ao objeto de estudo, como um estudo de caso, pois proporciona uma visão global do problema ao identificar fatores que influenciam ou são influenciados (GIL, 2007). Trata-se, ainda, de um estudo descritivo dada a observação, análise e registro dos dados, com o objetivo de classificá-los e analisá- 


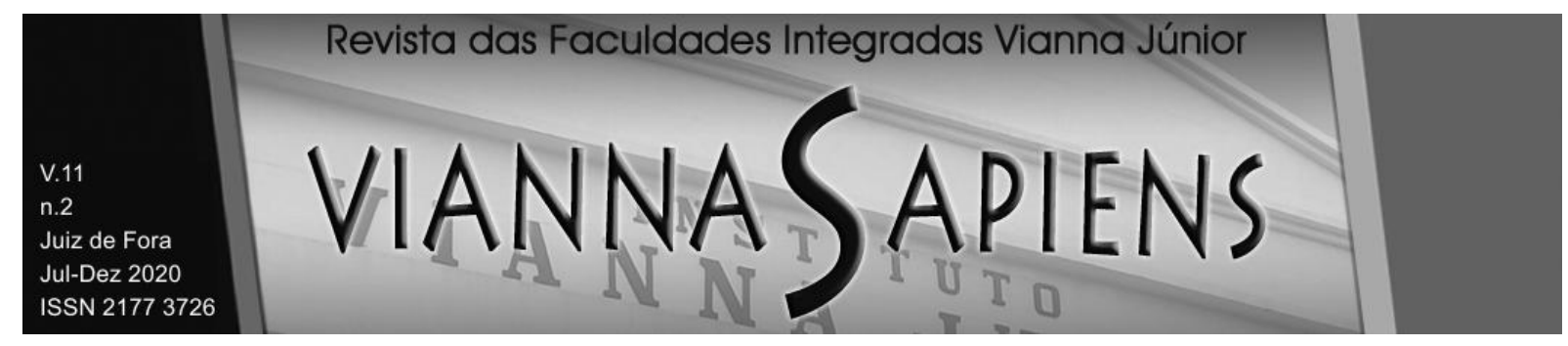

los, sem qualquer interferência do pesquisador (ANDRADE, 2002; PRODANOV, FREITAS, 2013).

A coleta de dados se deu a partir de análise documental, em arquivos oficiais da empresa mantidos pelo gestor e pela sua colaboradora (como notas fiscais e diário de anotações). Primeiramente, foram obtidas as descrições dos principais produtos que a empresa comercializa, bem como a quantidade vendida no período em estudo, de fevereiro a junho, o preço unitário de venda e custo unitário dos produtos. Outro procedimento adotado para a coleta de dados foi a pesquisaação que, segundo Thiollent (1986), onde se busca a solução de determinado problema, sendo que tanto o pesquisador quanto os participantes da situação problema estão envolvidos de maneira cooperada.

Inicialmente, foram realizadas visitas in loco, para analisar sua situação atual, seu funcionamento, como ela era administrada e como funcionava seu controle de estoque. Em momento posterior, iniciou-se a coleta, sendo autorizado o acesso e registro de dados adicionais.

Com os dados reunidos, realizou-se a organização dos mesmos em planilhas do Software Microsoft Office Excel $\AA$. Feito isso, os itens foram classificados segundo a curva $A B C$, conforme o lucro líquido. Como os itens classe $A$ são os mais importantes, realizou-se um estudo mais aprofundado e uma nova coleta de dados.

Por fim, foram propostas melhorias para a gestão de estoque dos itens classe A, baseando-se nos resultados obtidos através dos cálculos dos índices de desempenho, como o estoque de segurança (ES), ponto de reposição (PR) e lote econômico de compras (LEC), para que o gestor identifique quando e quanto comprar dos materiais mais importantes em termos de lucro. Já para os itens classe $\mathrm{B}$ e $\mathrm{C}$, realizou-se uma análise mais superficial. 


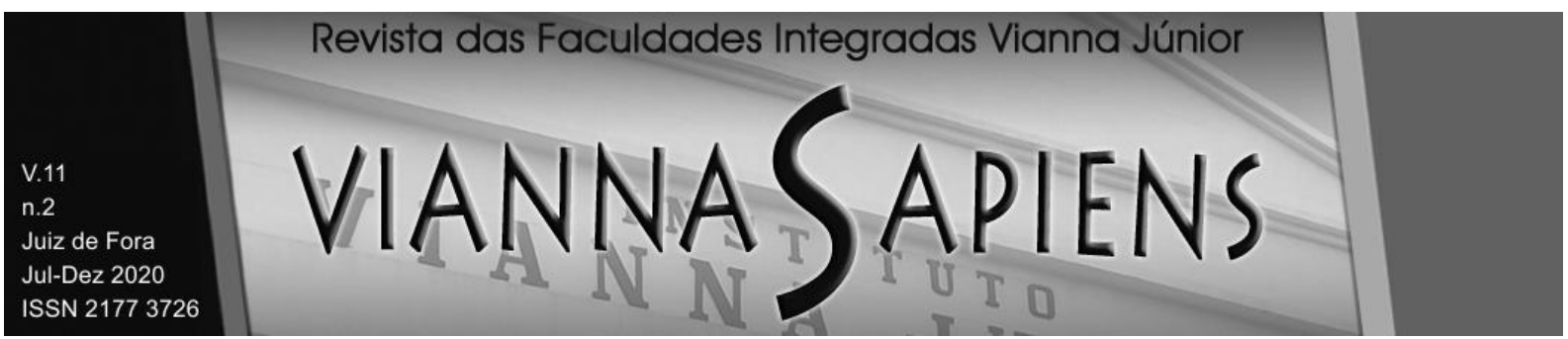

\section{RESULTADOS E DISCUSSÃO}

\subsection{Definição da amostra e sistema de controle de estoque da empresa}

A empresa em estudo é um supermercado de pequeno porte, que atua há quase 30 anos no mercado varejista. Para o início do estudo de caso, realizou-se um levantamento sobre o fluxo de saída dos produtos e o histórico de demanda da empresa. Estas etapas foram feitas com o auxílio do gestor e de sua colaboradora, a fim de identificar e analisar os principais grupos comercializados.

A empresa trabalha com uma ampla variedade de itens, mas o presente estudo de caso não abrangeu a todos. Foram selecionados os itens com demanda constante de consumo - premissa para uso do modelo LEC que torna possível controlar os estoques, uma vez que o ressuprimento é contínuo e/ou periódico (CHING, 2001).

Depois, os produtos foram categorizados a partir de classificação sugerida por SEBRAE (2000). Como resultado, selecionaram-se itens de gêneros alimentícios (que incluem cereais, grãos e farináceos, conservas e enlatados, matinal, bomboniere, congelados, frios e laticínios), bebidas alcóolicas e não alcóolicas, produtos de higiene pessoal e residencial, alguns itens do setor de papelaria, ração para animais domésticos e produtos diversos, como o gás de cozinha.

A empresa não possui sistema informatizado para controle de estoque - 0 registro é feito manualmente. Mas, nem todos os itens vendidos são controlados; geralmente, são mantidas anotações de itens vendidos a prazo.

O controle de compra das mercadorias é realizado através das notas fiscais. No entanto, em se tratando do estoque, apenas o controle de entrada de itens é insuficiente para controlá-lo e dimensioná-lo. O ideal seria adotar um software de baixo custo e de fácil acesso, para melhorar o registro e armazenamento dos dados. Porém, devido às particularidades da empresa, não foi possível implementar o uso de sistema informatizado. 


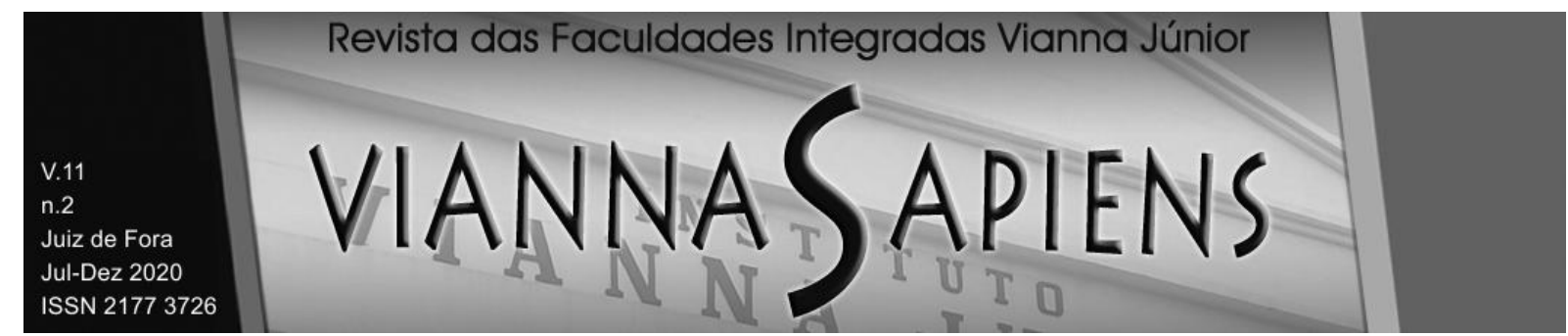

\subsection{Aplicação da curva ABC}

No primeiro momento, os dados mantidos pela empresa eram insuficientes para realizar a classificação da curva $\mathrm{ABC}$, uma vez que a quantidade de itens vendidos (saída) não era totalmente registrada. Para melhorar a precisão do controle de dados, elaborou-se um modelo de planilha de anotações para que a empresa documentasse, diariamente, os produtos vendidos e as respectivas quantidades.

Priorizou-se a criação de uma planilha de fácil preenchimento manual. Os dados foram posteriormente repassados para planilhas do MS Excel $\Theta$. Para cada mês, realizou-se a contagem final das quantidades vendidas.

Após a coleta de dados, foi possível organizá-los para a elaboração da curva $A B C$, de modo a identificar quais os itens (de demanda constante) são mais representativos, em termo de lucro. A classificação se deu por:

a) Identificação numérica dos itens;

b) Descrição dos itens analisados, com o nome e quantidades;

c) Identificação quantidade de vendas registrada durante o período de estudo;

d) Identificação do custo unitário de aquisição dos itens. Em casos de análise de diferentes marcas de um mesmo item, obteve-se o custo médio e preço unitário do produto;

e) Obtenção do lucro líquido, considerando a margem de contribuição de cada produto. Segundo Peinado e Graeml (2007), a margem de contribuição unitária $\left(M C_{U n i t}\right)$ é a diferença entre o preço de venda unitário $(P V)$ e o custo variável unitário $(\mathrm{Cu})$, sendo posteriormente multiplicada pela quantidade vendida para apontar o lucro líquido. Os custos operacionais e de impostos não foram considerados, dada a simplificação adotada, e o de aluguel também não, uma vez que os itens são armazenados em espaço próprio da empresa. 


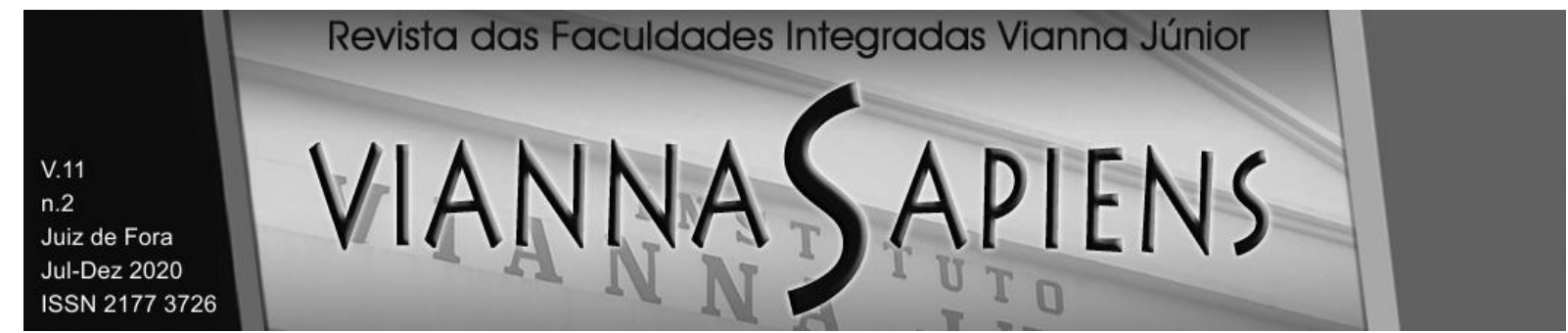

f) Após obter o lucro líquido de todos os produtos, os dados foram reordenados de maneira decrescente, considerando a classificação dos itens conforme curva ABC;

g) Elaboração da porcentagem individual de lucro, por item, em relação ao lucro líquido total;

h) Elaboração da porcentagem acumulada de lucro, referente à soma da porcentagem de lucro do item com a porcentagem de lucro de todos os itens anteriores a ele;

i) Obtenção da porcentagem de participação de cada item, com relação ao total de produtos estudados. Essa porcentagem é resultante da divisão de cada insumo pela quantidade total de itens e o valor encontrado não se refere à quantidade vendida. Como o estudo abrangeu 103 itens diferentes, cada um representa $0,97 \%$ do total de itens. Através do critério de corte utilizado, buscouse identificar os $20 \%$ dos itens mais representativos. Aqui, os itens receberam porcentagens iguais pois o foco é o lucro líquido que cada um retorna;

j) Obtenção da porcentagem acumulada de cada item, referente à soma da porcentagem do item com a de todos os itens anteriores a ele;

k) Classificação $A B C$ dos itens estudados, utilizando fórmulas e formatações do software MS Excel.

Optou-se por classificar os itens com base no lucro líquido, como sugerido por Luchezzi (2015). Com a classificação, foi possível identificar os itens que são mais representativos em termo de lucro. A porcentagem de itens foi considerada para a definição da priorização da curva ABC (Tabela 2).

Tabela 2: Classificação $A B C$ dos itens por lucro líquido.

\begin{tabular}{clccccc}
\hline Item & \multicolumn{1}{c}{ Descrição } & Lucro \% & Lucro acum. \% & $\begin{array}{c}\text { Itens } \\
\%\end{array}$ & $\begin{array}{c}\text { Itens acum. } \\
\%\end{array}$ & Classe \\
\hline 99 & Gás 13 kg & 8,21 & 8,21 & 0,97 & 0,97 & $\mathrm{~A}$ \\
51 & Linguiça kg & 3,20 & 11,40 & 0,97 & 1,94 & $\mathrm{~A}$ \\
56 & Refrigerante 2 I & 3,02 & 14,42 & 0,97 & 2,91 & $\mathrm{~A}$ \\
79 & Desodorante aerossol 150 ml & 2,39 & 16,81 & 0,97 & 3,88 & $\mathrm{~A}$ \\
81 & Creme dental 90 g & 2,30 & 19,11 & 0,97 & 4,85 & $\mathrm{~A}$ \\
54 & Água mineral 20 I & 2,08 & 21,19 & 0,97 & 5,83 & $\mathrm{~A}$
\end{tabular}




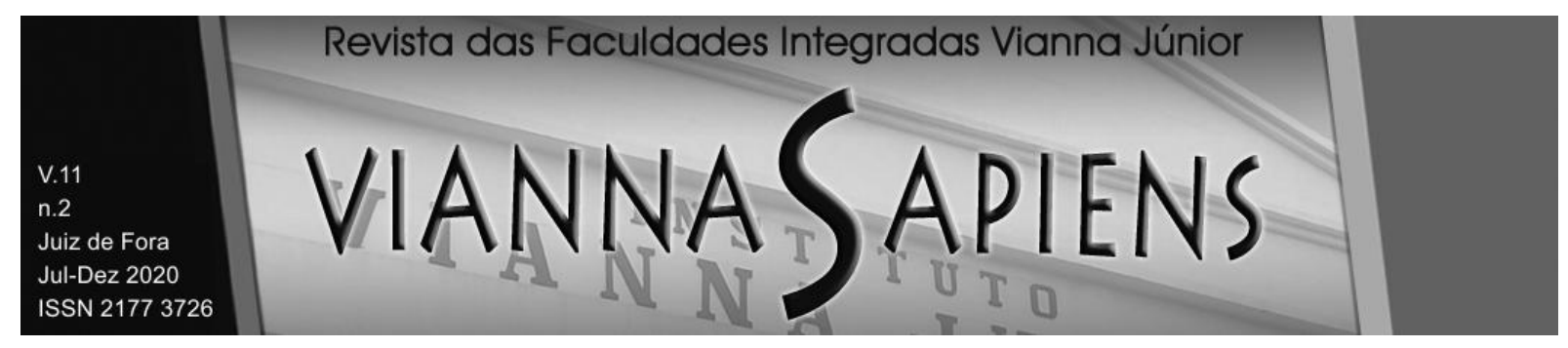

\begin{tabular}{|c|c|c|c|c|c|}
\hline 58 & Cerveja 350 ml & 1,96 & 23,15 & 0,97 & 6,80 \\
\hline 37 & Biscoito recheado $130 \mathrm{~g}$ & 1,90 & 25,05 & 0,97 & 7,77 \\
\hline 67 & Amaciante 2I & 1,77 & 26,82 & 0,97 & 8,74 \\
\hline 1 & Arroz $5 \mathrm{~kg}$ & 1,68 & 28,50 & 0,97 & 9,71 \\
\hline 72 & Cloro 21 & 1,68 & 30,18 & 0,97 & 10,68 \\
\hline 78 & Desodorante rollon $50 \mathrm{ml}$ & 1,66 & 31,84 & 0,97 & 11,65 \\
\hline 14 & Café $500 \mathrm{~g}$ & 1,57 & 33,41 & 0,97 & 12,62 \\
\hline 64 & Sabão em pó 1 kg & 1,55 & 34,97 & 0,97 & 13,59 \\
\hline 69 & Pano de chão unidade & 1,55 & 36,52 & 0,97 & 14,56 \\
\hline 87 & Sabonete unidade & 1,54 & 38,06 & 0,97 & 15,53 \\
\hline 50 & Frango kg & 1,53 & 39,59 & 0,97 & 16,50 \\
\hline 93 & Ração para galinha kg & 1,53 & 41,12 & 0,97 & 17,48 \\
\hline 2 & Açúcar $5 \mathrm{~kg}$ & 1,53 & 42,65 & 0,97 & 18,45 \\
\hline 19 & Farinha de mandioca $1 \mathrm{~kg}$ & 1,46 & 44,11 & 0,97 & 19,42 \\
\hline 89 & Fralda descartável pacote & 1,39 & 45,50 & 0,97 & 20,39 \\
\hline 92 & Ração para gato kg & 1,38 & 46,88 & 0,97 & 21,36 \\
\hline 41 & Mirabel $115 \mathrm{~g}$ & 1,35 & 48,22 & 0,97 & 22,33 \\
\hline 80 & Papel higiênico 4 unid. & 1,31 & 49,54 & 0,97 & 23,30 \\
\hline 68 & Veja $500 \mathrm{ml}$ & 1,25 & 50,79 & 0,97 & 24,27 \\
\hline 97 & Folha A4 100 folhas & 1,13 & 51,91 & 0,97 & 25,24 \\
\hline 36 & Leite integral 1। & 1,12 & 53,03 & 0,97 & 26,21 \\
\hline 82 & Escova de dente unid. & 1,12 & 54,15 & 0,97 & 27,18 \\
\hline 15 & Café $250 \mathrm{~g}$ & 1,09 & 55,24 & 0,97 & 28,16 \\
\hline 73 & Pinho 1I & 1,08 & 56,32 & 0,97 & 29,13 \\
\hline 49 & Bananinha chips $50 \mathrm{~g}$ & 1,08 & 57,39 & 0,97 & 30,10 \\
\hline 40 & Biscoito maizena $200 \mathrm{~g}$ & 1,06 & 58,45 & 0,97 & 31,07 \\
\hline 44 & Bala unid. & 1,05 & 59,49 & 0,97 & 32,04 \\
\hline 84 & Acetona $100 \mathrm{ml}$ & 1,03 & 60,53 & 0,97 & 33,01 \\
\hline 88 & Absorvente pacote com $8 u$. & 1,01 & 61,54 & 0,97 & 33,98 \\
\hline 57 & Refrigerante $350 \mathrm{ml}$ & 1,01 & 62,55 & 0,97 & 34,95 \\
\hline 83 & Tintura para cabelo kit & 1,00 & 63,55 & 0,97 & 35,92 \\
\hline 91 & Ração para cachorro kg & 0,96 & 64,51 & 0,97 & 36,89 \\
\hline 75 & Água sanitária 1। & 0,96 & 65,46 & 0,97 & 37,86 \\
\hline 90 & Lenço umedecido 50 unid. & 0,95 & 66,41 & 0,97 & 38,83 \\
\hline 29 & Molho inglês $150 \mathrm{ml}$ & 0,95 & 67,36 & 0,97 & 39,81 \\
\hline 59 & Detergente $500 \mathrm{ml}$ & 0,95 & 68,31 & 0,97 & 40,78 \\
\hline 102 & Vassoura unid. & 0,95 & 69,26 & 0,97 & 41,75 \\
\hline 34 & Creme de leite $200 \mathrm{ml}$ & 0,94 & 70,20 & 0,97 & 42,72 \\
\hline 98 & Folha A4 500 folhas & 0,94 & 71,14 & 0,97 & 43,69 \\
\hline 16 & Óleo 900 ml & 0,93 & 72,07 & 0,97 & 44,66 \\
\hline 23 & Maionese $250 \mathrm{~g}$ & 0,92 & 72,99 & 0,97 & 45,63 \\
\hline 39 & Biscoito salpet $200 \mathrm{~g}$ & 0,91 & 73,90 & 0,97 & 46,60 \\
\hline 42 & Chips $50 \mathrm{~g}$ & 0,88 & 74,78 & 0,97 & 47,57 \\
\hline 30 & Molho de pimenta $150 \mathrm{ml}$ & 0,84 & 75,62 & 0,97 & 48,54 \\
\hline 100 & Carvão 5 kg & 0,83 & 76,46 & 0,97 & 49,51 \\
\hline 11 & Amendoim $500 \mathrm{~g}$ & 0,83 & 77,28 & 0,97 & 50,49 \\
\hline 52 & Manteiga $500 \mathrm{~g}$ & 0,82 & 78,10 & 0,97 & 51,46 \\
\hline 48 & Pipoca doce $50 \mathrm{~g}$ & 0,80 & 78,90 & 0,97 & 52,43 \\
\hline 35 & Leite condensado $200 \mathrm{ml}$ & 0,80 & 79,69 & 0,97 & 53,40 \\
\hline 47 & Doce unid. & 0,77 & 80,46 & 0,97 & 54,37 \\
\hline 43 & Caixa de bombom $300 \mathrm{~g}$ & 0,76 & 81,23 & 0,97 & 55,34 \\
\hline 22 & Maionese $500 \mathrm{~g}$ & 0,72 & 81,95 & 0,97 & 56,31 \\
\hline 45 & Chiclete unid. & 0,70 & 82,65 & 0,97 & 57,28 \\
\hline
\end{tabular}

\begin{tabular}{l} 
A \\
$A$ \\
$A$ \\
$A$ \\
$A$ \\
$A$ \\
$A$ \\
$A$ \\
$A$ \\
$A$ \\
$A$ \\
$A$ \\
$A$ \\
$A$ \\
$A$ \\
$B$ \\
$B$ \\
$B$ \\
$B$ \\
$B$ \\
$B$ \\
$B$ \\
$B$ \\
$B$ \\
$B$ \\
$B$ \\
$B$ \\
$B$ \\
$B$ \\
$B$ \\
$B$ \\
$B$ \\
$B$ \\
$B$ \\
$B$ \\
$B$ \\
$B$ \\
$B$ \\
$B$ \\
$B$ \\
$B$ \\
$B$ \\
$B$ \\
$B$ \\
$B$ \\
$B$ \\
$C$ \\
$C$ \\
$C$ \\
$C$ \\
$C$ \\
$C$ \\
$C$ \\
$C$ \\
\hline
\end{tabular}




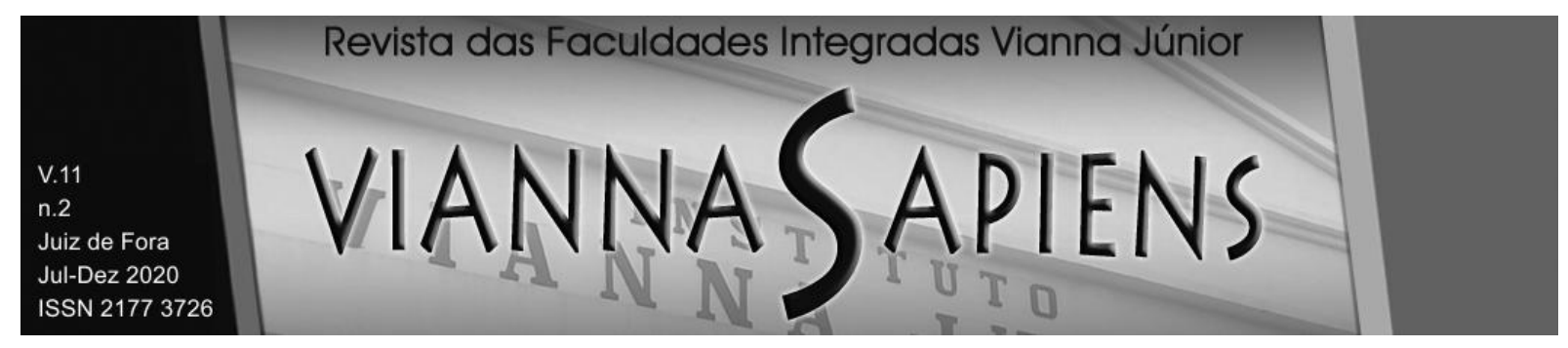

\begin{tabular}{|c|c|c|c|c|c|c|}
\hline 26 & Milho verde $200 \mathrm{~g}$ & 0,69 & 83,34 & 0,97 & 58,25 & C \\
\hline 71 & Álcool 1। & 0,65 & 83,98 & 0,97 & 59,22 & C \\
\hline 74 & Pinho 500 ml & 0,61 & 84,60 & 0,97 & 60,19 & C \\
\hline 53 & Manteiga $250 \mathrm{~g}$ & 0,61 & 85,21 & 0,97 & 61,17 & C \\
\hline 101 & Rodo unid. & 0,61 & 85,81 & 0,97 & 62,14 & C \\
\hline 28 & Tempero pronto $1 \mathrm{~kg}$ & 0,58 & 86,40 & 0,97 & 63,11 & C \\
\hline 25 & Batata palha $130 \mathrm{~g}$ & 0,53 & 86,93 & 0,97 & 64,08 & C \\
\hline 76 & Cera líquida 1। & 0,53 & 87,45 & 0,97 & 65,05 & C \\
\hline 60 & Limpa alumínio 500 ml & 0,52 & 87,97 & 0,97 & 66,02 & C \\
\hline 20 & Ovos dúzia & 0,51 & 88,48 & 0,97 & 66,99 & C \\
\hline 8 & Fubá 1 kg & 0,50 & 88,98 & 0,97 & 67,96 & C \\
\hline 17 & Farinha trigo $\mathrm{c} /$ fermento $1 \mathrm{~kg}$ & 0,50 & 89,47 & 0,97 & 68,93 & C \\
\hline 70 & Flanela unidade & 0,49 & 89,96 & 0,97 & 69,90 & C \\
\hline 3 & Feijão 1 kg & 0,48 & 90,44 & 0,97 & 70,87 & C \\
\hline 55 & Água mineral $500 \mathrm{ml}$ & 0,48 & 90,92 & 0,97 & 71,84 & C \\
\hline 31 & Orégano $4 \mathrm{~g}$ & 0,47 & 91,39 & 0,97 & 72,82 & C \\
\hline 86 & Água oxigenada $90 \mathrm{ml}$ & 0,45 & 91,84 & 0,97 & 73,79 & $\mathrm{C}$ \\
\hline 85 & Amônia 100 ml & 0,44 & 92,28 & 0,97 & 74,76 & C \\
\hline 65 & Sabão em pó $500 \mathrm{~g}$ & 0,43 & 92,71 & 0,97 & 75,73 & C \\
\hline 94 & Caneta & 0,41 & 93,13 & 0,97 & 76,70 & C \\
\hline 63 & Esponja unidade & 0,41 & 93,54 & 0,97 & 77,67 & C \\
\hline 18 & Farinha de trigo sem fermento $1 \mathrm{~kg}$ & 0,41 & 93,94 & 0,97 & 78,64 & C \\
\hline 62 & Esponja de aço pacote com 8 unid & 0,40 & 94,34 & 0,97 & 79,61 & C \\
\hline 13 & Mistura de bolo $400 \mathrm{~g}$ & 0,40 & 94,74 & 0,97 & 80,58 & C \\
\hline 61 & Sabão de barra $200 \mathrm{~g}$ & 0,39 & 95,13 & 0,97 & 81,55 & C \\
\hline 10 & Millho de pipoca $500 \mathrm{~g}$ & 0,39 & 95,52 & 0,97 & 82,52 & C \\
\hline 12 & Canjicão $500 \mathrm{~g}$ & 0,39 & 95,91 & 0,97 & 83,50 & C \\
\hline 103 & Balde $10 \mathrm{I}$ & 0,37 & 96,28 & 0,97 & 84,47 & $\mathrm{C}$ \\
\hline 9 & Pipoca de microondas $100 \mathrm{~g}$ & 0,35 & 96,62 & 0,97 & 85,44 & C \\
\hline 38 & Biscoito água e sal $200 \mathrm{~g}$ & 0,34 & 96,97 & 0,97 & 86,41 & C \\
\hline 66 & Sabão de coco $100 \mathrm{~g}$ & 0,31 & 97,28 & 0,97 & 87,38 & C \\
\hline 27 & Tempero pronto $300 \mathrm{~g}$ & 0,31 & 97,59 & 0,97 & 88,35 & C \\
\hline 21 & Molho de tomate $190 \mathrm{~g}$ & 0,30 & 97,89 & 0,97 & 89,32 & C \\
\hline 46 & Pirulito unid. & 0,28 & 98,17 & 0,97 & 90,29 & C \\
\hline 96 & Borracha unid. & 0,26 & 98,43 & 0,97 & 91,26 & C \\
\hline 95 & Lápis unid. & 0,22 & 98,65 & 0,97 & 92,23 & C \\
\hline 77 & Cotonete caixa com 75 unid. & 0,21 & 98,86 & 0,97 & 93,20 & C \\
\hline 5 & Macarrão $500 \mathrm{~g}$ & 0,21 & 99,06 & 0,97 & 94,17 & C \\
\hline 33 & Pimenta do reino $40 \mathrm{~g}$ & 0,20 & 99,26 & 0,97 & 95,15 & C \\
\hline 7 & Canjiquinha $500 \mathrm{~g}$ & 0,19 & 99,45 & 0,97 & 96,12 & C \\
\hline 6 & Canjiquinha $1 \mathrm{~kg}$ & 0,18 & 99,64 & 0,97 & 97,09 & $\mathrm{C}$ \\
\hline 32 & Folha de louro $4 \mathrm{~g}$ & 0,16 & 99,79 & 0,97 & 98,06 & C \\
\hline 4 & Sal $1 \mathrm{~kg}$ & 0,14 & 99,94 & 0,97 & 99,03 & C \\
\hline \multirow[t]{2}{*}{24} & Azeitona $100 \mathrm{~g}$ & 0,06 & 100,00 & 0,97 & 100,00 & C \\
\hline & TOTAL & 100,00 & & 100,00 & & \\
\hline
\end{tabular}

Fonte: Autoria própria.

Os itens que apresentaram uma porcentagem acumulada menor ou igual a $20 \%$, foram classificados como classe A. Os que apresentaram uma porcentagem acumulada entre $20 \%$ e $50 \%$ foram classificados como classe B (30\% dos produtos). 


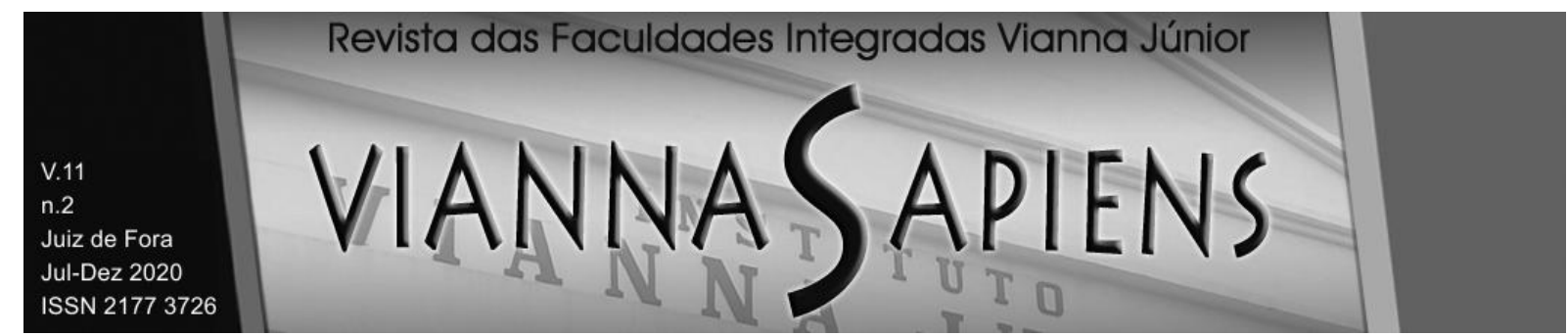

Por fim, os itens que apresentaram porcentagem acumulada entre 50\% e $100 \%$ foram classificados como classe $\mathrm{C}$, representando $50 \%$ dos produtos estudados.

$\mathrm{O}$ critério de corte utilizado se deveu à característica dos dados. Como o lucro líquido de cada produto é pequeno, seu valor acumulado aumenta gradativamente. Se o corte para a Classe A fosse os $80 \%$ de lucro acumulado, seriam incorporados mais de $50 \%$ dos produtos, o que inviabilizaria um estudo detalhado.

A Figura 2 apresenta a Curva ABC. Neste gráfico, está a porcentagem de lucro individual de cada item (representado à esquerda do gráfico) e a porcentagem de lucro acumulada (representada à direita do gráfico).

Figura 2: Curva da classificação ABC por lucro líquido

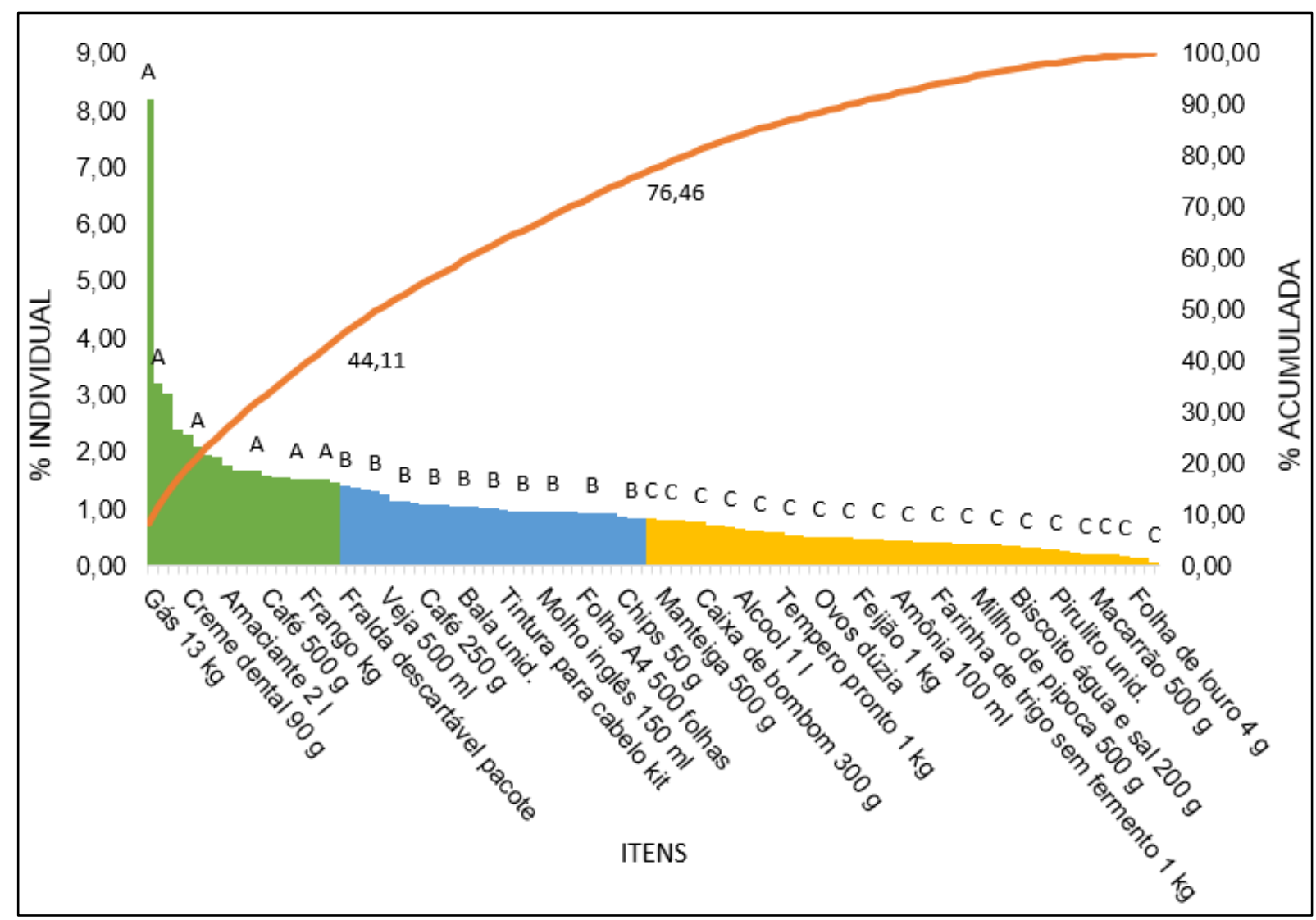

Fonte: Autoria própria. 


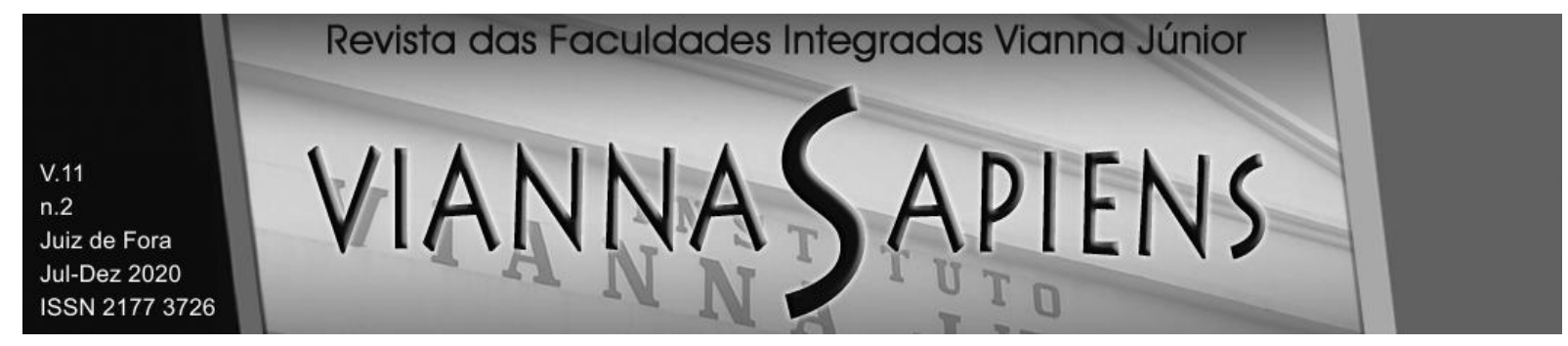

Os itens pertencentes à classe $A$ (aproximadamente $20 \%$ do total) foram responsáveis por $44,11 \%$ do lucro líquido total. Já o grupo da classe B (aproximadamente $30 \%$ dos itens) ficou com aproximadamente $32,35 \%$ do lucro total. Por último, a classe $\mathrm{C}$, apesar de conter a maior parte dos itens (cerca de $50 \%$ ), reflete $23,54 \%$ do lucro líquido total, sendo o grupo de menor representatividade em termos de lucro. A Tabela 3 mostra um resumo da importância relativa obtida pela classificação $A B C$.

Tabela 3 - Resultado da classificação ABC

\begin{tabular}{cccc}
\hline Classe & Itens \% & Lucro \% & Importância relativa \\
\hline A & 19,42 & 44,11 & Alta \\
B & 30,10 & 32,35 & Intermediária \\
C & 50,48 & 23,54 & Baixa \\
\hline
\end{tabular}

Fonte: Autoria própria.

Os índices de desempenho de estoque serão obtidos para os itens da classe A, o que baseará decisões mais objetivas e eficientes para gestão de estoques. $A$ Tabela 4 apresenta os resultados obtidos para Consumo Médio (CM), o Estoque de Segurança (ES), o Ponto de Reposição (PR), o Lote Econômico de Compra (LEC) e o Estoque Máximo $\left(E_{\text {máx }}\right)$ - Equações de 1 a 5 , respectivamente.

O consumo médio mensal foi obtido através da média de venda registrada entre fevereiro e junho. Já o desvio padrão foi calculado a partir da quantidade vendida em cada mês do período estudado e a média mensal de vendas.

Quanto ao coeficiente de grau de risco $(k)$, considerou-se um grau de atendimento de 99,9\%, que resulta em $k$ igual a 3,090 - conforme Tabela 1. 0 estoque de segurança foi arredondado para o próximo número inteiro, por se tratar de unidades. 


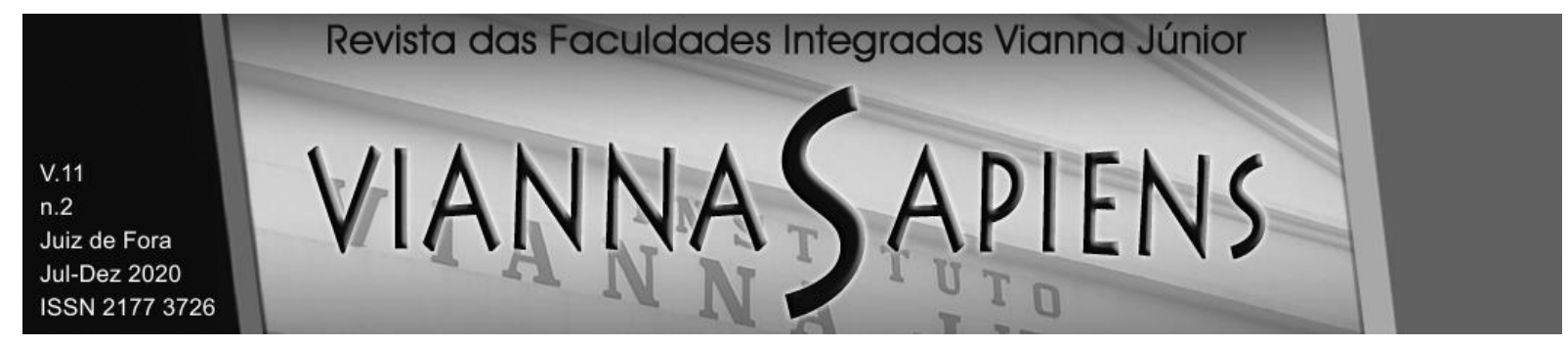

Tabela 4 - Índices de desempenho de estoque dos itens classe A.

\begin{tabular}{lccccccc}
\hline \multicolumn{1}{c}{ Descrição } & CM Mensal & $\boldsymbol{\delta}$ & ES & TR & PR & LEC & E $_{\text {Máx }}$ \\
\hline Gás 13 kg & 21,40 & 1,82 & 6 & 0,13 & 9 & 20 & 26 \\
Linguiça kg & 41,40 & 3,51 & 11 & 0,10 & 16 & 58 & 69 \\
Refrigerante 2 I & 57,60 & 2,61 & 9 & 0,10 & 15 & 85 & 94 \\
Desodorante aerossol 150 ml & 26,20 & 1,64 & 6 & 0,23 & 13 & 41 & 47 \\
Creme dental 90 g & 51,40 & 1,82 & 6 & 0,23 & 18 & 128 & 134 \\
Água mineral 20 I & 45,00 & 2,55 & 8 & 0,23 & 19 & 94 & 102 \\
Cerveja 350 ml & 75,80 & 4,09 & 13 & 0,10 & 21 & 131 & 144 \\
Biscoito recheado 130 g & 64,80 & 4,60 & 15 & 0,23 & 31 & 164 & 179 \\
Amaciante 2 I & 34,20 & 1,48 & 5 & 0,23 & 13 & 59 & 64 \\
Arroz 5 kg & 26,20 & 4,82 & 15 & 1,00 & 42 & 40 & 55 \\
Cloro 2 I & 45,20 & 3,56 & 12 & 0,23 & 23 & 129 & 141 \\
Desodorante rollon 50 ml & 28,40 & 1,14 & 4 & 0,23 & 11 & 53 & 57 \\
Café 500 g & 49,20 & 3,11 & 10 & 0,23 & 22 & 64 & 74 \\
Sabão em pó 1 kg & 26,20 & 1,30 & 5 & 0,23 & 12 & 52 & 57 \\
Pano de chão unidade & 28,40 & 1,14 & 4 & 0,23 & 11 & 75 & 79 \\
Sabonete unidade & 70,80 & 3,03 & 10 & 0,23 & 27 & 210 & 220 \\
Frango kg & 50,00 & 2,35 & 8 & 0,23 & 20 & 77 & 85 \\
Ração para galinha kg & 68,00 & 2,12 & 7 & 0,23 & 23 & 134 & 141 \\
Açúcar 5 kg & 29,60 & 2,30 & 8 & 0,23 & 15 & 49 & 57 \\
Farinha de mandioca 1 Kg & 35,60 & 0,89 & 3 & 0,23 & 12 & 91 & 94 \\
\hline
\end{tabular}

Para o cálculo do ponto de reposição (PR), foram obtidos os tempos de reposição (TR) de cada um dos itens e calculado em meses (considerou-se o mês comercial de 30 dias). Assim como o ES, o PR também foi arredondado para o próximo número inteiro, por se tratar de unidades. O PR encontrado para o gás, por exemplo, foi de 9 unidades; ou seja, sempre que o estoque do gás chegar a essa quantidade, o proprietário deverá fazer um novo pedido do item.

Após definir quando comprar, é importante quantificar. O LEC indica a quantidade ideal a ser comprada de cada pedido, de maneira a torná-lo mais economicamente viável, equilibrando o custo de pedido e de estocagem ao também considerar a demanda no período e o custo de oportunidade.

O custo de pedido, neste estudo, independe do tamanho do lote de compras, e considerou que a mão de obra do gestor custa aproximadamente $R \$ 0,29$ por minuto. O custo unitário do pedido foi obtido, então, através da multiplicação do 


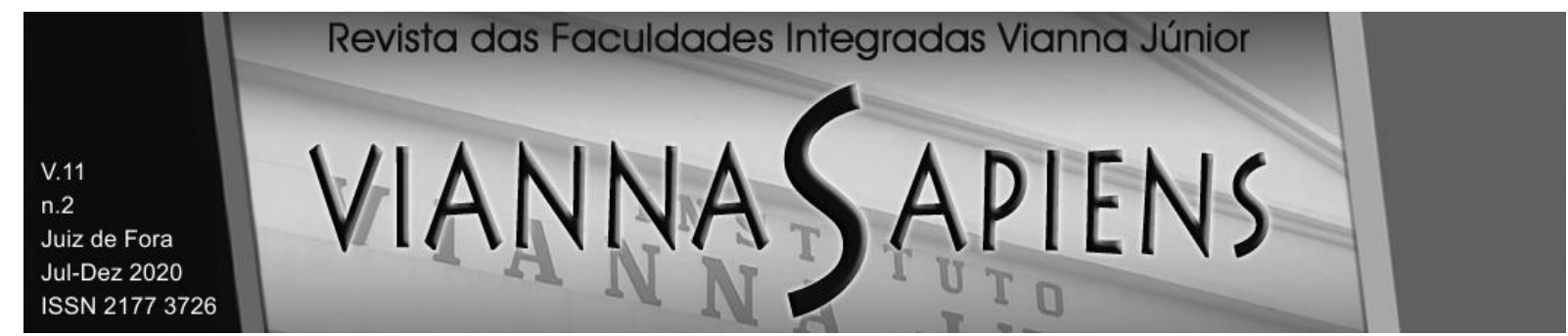

tempo gasto para fazer pedido (em minutos) e o custo da mão de obra do gestor (em $\mathrm{R} \$$ /minuto).

A demanda do período foi calculada através do CM multiplicado por 12 (quantidade de meses do ano). O custo total com pedidos foi definido através do custo de cada pedido multiplicado pela quantidade de pedidos no período.

Para o custo de oportunidade $(t)$, optou-se pela taxa de Certificado de Depósito Interbancário (CDI), investimento opcional ao empreendedor, dado o baixo risco. De acordo com o Banco Central do Brasil (2019), o CDI se refere à taxa cobrada pelos bancos para empréstimo de valores a outros bancos. Então, o cálculo do LEC tomou como base a taxa anual de juros $(t)$ de $0,0642(6,42 \%$, no período estudado) para todos os itens.

Por fim, o custo unitário do produto se refere ao custo que o gestor tem ao comprar cada produto. Com essas variáveis, foi possível calcular o LEC para os produtos classe $A$, com o auxílio da Equação 4. Assim, o estoque máximo ( $\left.E_{\text {Máx }}\right)$ foi obtido utilizando a Equação 5 e representa a quantidade máxima planejada para 0 item, obtida através da soma do LEC com o ES obtidos.

\subsection{Representação gráfica dos índices de desempenho de estoque}

As representações gráficas mostradas a seguir podem ser aplicadas a todos os itens tidos como classe A no estudo, uma vez que seus índices de desempenho de estoque foram calculados. Para exemplificar, utilizou-se o gás como modelo, que foi o item mais representativo obtido na classificação ABC. A Figura 3 apresenta graficamente o LEC obtido para o gás, com relação entre custo $(R \$)$ e quantidades. 


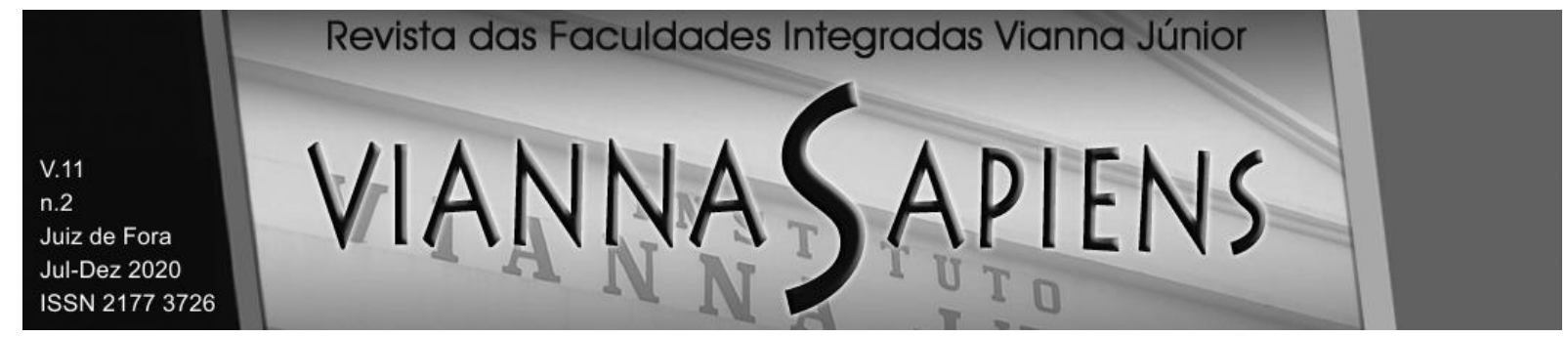

Figura 3 - Representação gráfica do LEC para o gás

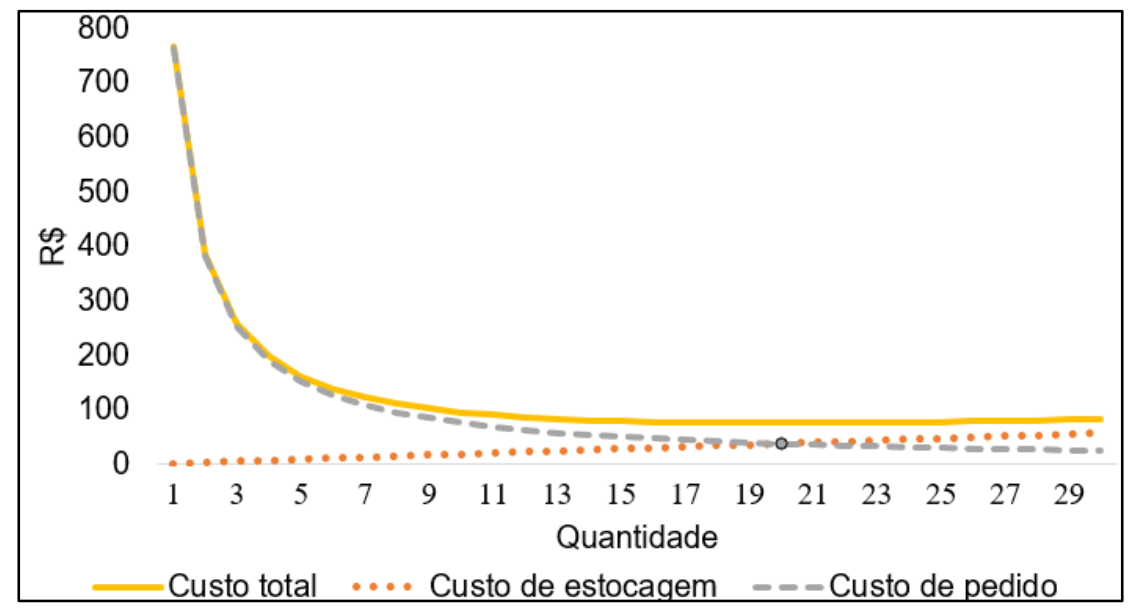

Fonte: Autoria própria.

Nota-se a relação entre os custos estocagem e de pedido para o gás. O custo de estocagem, de fato, aumenta com a quantidade, pois, quanto maior for o lote compra, mais unidades serão armazenadas, e maior será o custo para estocá-las. Neste caso, maior será também o capital investido e, consequentemente, os juros aplicados a ele.

Já o custo de pedido é inversamente proporcional à quantidade: quanto maior for o lote de compras, menor será a quantidade de pedidos necessária para suprir a demanda e, em consequência, menor será o custo com pedido. O LEC de 20 unidades encontrado para o gás é justamente a quantidade que iguala o custo de pedido com o custo de estocagem.

Essa quantidade, calculada pela Equação 4, é o ponto de equilíbrio entre os custos e é considerada a quantidade economicamente ideal para o lote de compras. A Figura 4 mostra graficamente os resultados obtidos para os índices de desempenho de estoque do gás e a relação entre esses índices. 


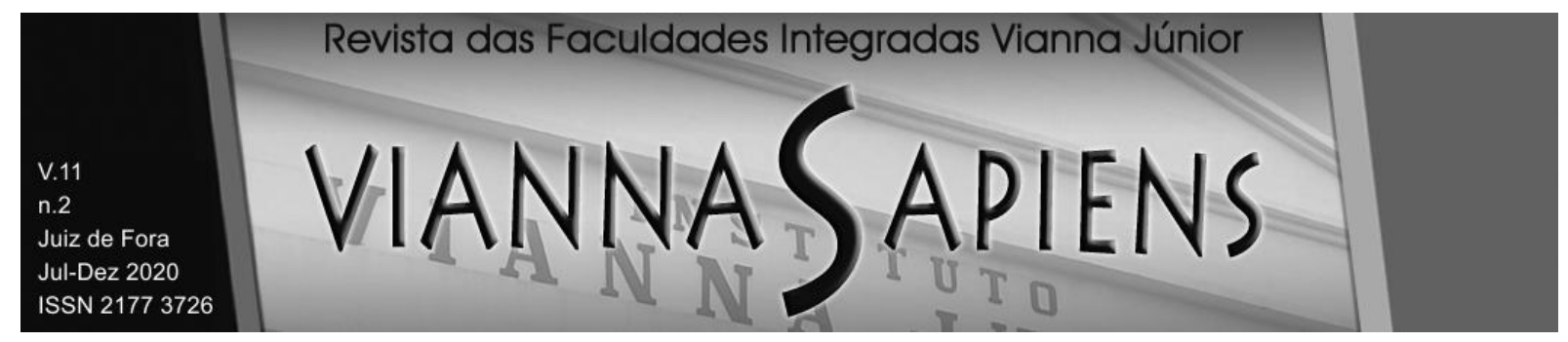

Figura 4 - Índices de desempenho de estoque para o gás

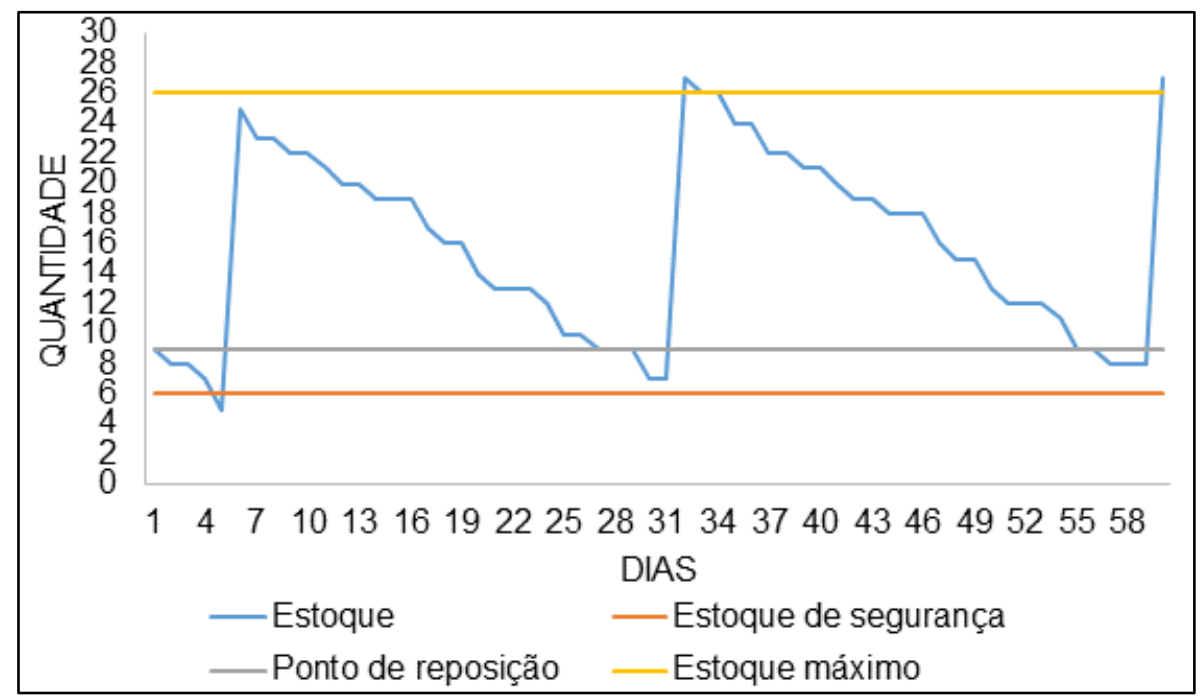

Fonte: Autoria própria.

Com ela, é visualizada a relação entre quantidade por dia, uma simulação baseada nos dados de consumo e estoque. Toda vez que a quantidade de gás em estoque chegar a 9 unidades (PR), significa que um novo pedido deverá ser feito. Esse pedido chegará após 4 dias (TR). Em alguns casos, o estoque ultrapassou a o $E_{\text {máx }}$ pois, como é possível notar pelo gráfico acima, o LEC chegou ao estoque antes que o mesmo atingisse seu ponto mínimo de 6 unidades. Esse LEC é quantidade delimitada entre $\circ E_{\text {Máx }}$ e $\circ \mathrm{ES}$, sendo uma quantidade de 20 unidades, conforme mostrado na Tabela 5.

É importante ressaltar que, independente do tamanho do lote de compras, o estoque de segurança permanecerá inalterado. A quantidade máxima viável de estoque para o gás é de 26 unidades. Caso o estoque ultrapasse essa quantia, a empresa poderá ter prejuízo com o excesso de estoque, pois a demanda pode não ser capaz de absorver essa quantidade e os produtos tendem a ficar no estoque por um tempo maior. 


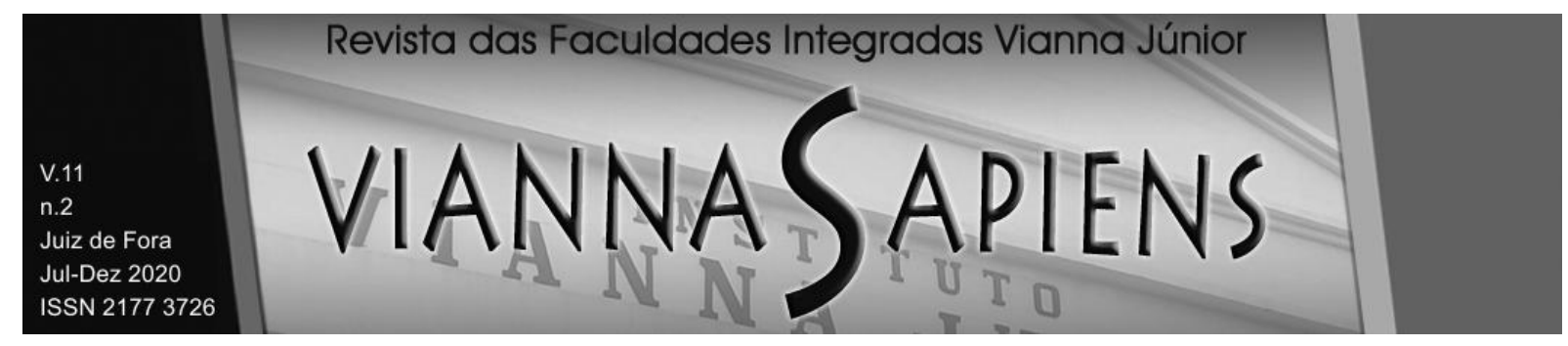

\section{CONSIDERAÇÕES FINAIS}

Considerando que o objetivo deste trabalho era propor gestão e dimensionamento de estoques a uma mercearia de pequeno porte, constata-se que o mesmo foi alcançado. Os itens foram classificados na curva $A B C$, sendo possível identificar a importância de cada item na composição do lucro líquido da empresa. Os índices de desempenho de estoques se mostraram eficazes pois, através deles, foi possível obter dados que nortearão a tomada de decisão da empresa.

Comparando os resultados obtidos com 0 atual sistema que a empresa trabalha, a quantidade do LEC calculada para os itens classe $A$ foram maiores que a atual quantidade que o gestor compra. A empresa trabalha com pequenos lotes de compras e realiza compras periodicamente, várias vezes em um determinado período.

A proposta de gestão de estoque para os itens classe A foi baseada nos índices de desempenho de estoque calculados durante o estudo. Diante disso, os resultados obtidos sugerem uma gestão de estoques baseada em uma quantidade maior para o lote de compras e um número reduzidos de pedido.

Isso significaria comprar mais produtos por cada pedido, e aumentar o intervalo entre uma compra e outra, fazendo com que o estoque gire um número menor de vezes no período. O que refletirá em redução de custos com os pedidos, de perdas com obsolescência (devido ao excesso de estoque) e de prejuízo (causado pela falta do produto).

A proposição do estudo não foi totalmente implementada. O registro manual dos dados implicou em algumas limitações do trabalho, como a precisão dos dados registrados e a dificuldade em se mensurar os custos relacionados ao estoque.

Como sugestão para próximos análises futuras, indica-se a aplicação da Curva $A B C$ por grupo de produtos, além de um estudo particular de itens que sofrem sazonalidade como forma de conhecer o seu comportamento e a sua representatividade na composição do lucro. Também seria viável um estudo de 


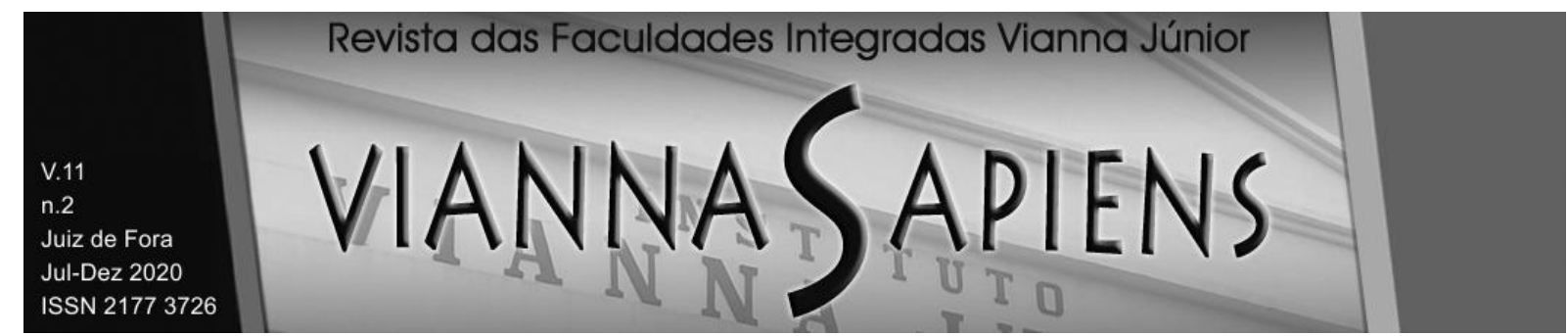

layout para verificar a melhor alocação do volume do LEC, dentro da capacidade de espaço.

Portanto, através do trabalho, foi possível aplicar algumas ferramentas e conceitos da gestão de estoque e perceber a importância e eficiência das mesmas. Esta é uma área de extrema importância para os supermercados e está relacionada com outros setores.

\section{REFERÊNCIAS}

ANDRADE, Maria Margarida de. Como preparar trabalhos para cursos de pósgraduação: noções práticas. 5. ed. São Paulo: Atlas, 2002.

BAILY, Peter. et al. Compras: princípios e administração. São Paulo: Atlas, 2000.

BOISSEL, JP. Planning of clinical trials. J Intern Med, v. 255, p. 427-38, 2004.

CARVALHO, José Mexia Crespo de. Logística. 3. ed. Lisboa: Sílabo, 2002.

CHIAVENATO, Idalberto. Administração de materiais: uma abordagem introdutória. Rio de Janeiro: Elsevier, 2005.

CHING, Hong Yuh. Gestão de estoques na cadeia de logística integrada. São Paulo: Atlas, 2001.

CORRÊA, Henrique L; CORRÊA, Carlos A. Administração de produção e operações: manufatura e serviços: uma abordagem estratégica. 3. ed. São Paulo: Atlas, 2012.

CORRÊA, Henrique L; et al. Planejamento, programação e controle da produção: MRP II / ERP: conceitos, uso e implantação: Base para Sap, Oracle Applications e outros softwares aplicados à gestão. 5. ed. São Paulo: Atlas, 2013. 


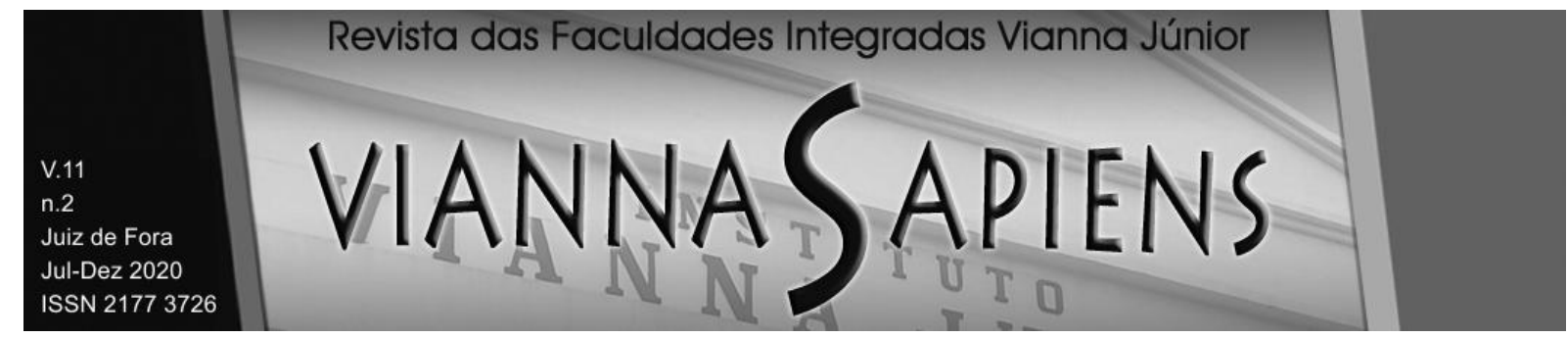

DIAS, Marco Aurélio P. Administração de materiais: uma abordagem logística. 4. ed. São Paulo: Atlas, 1993.

EVERTON JUNIOR, Antonio. MPE: avanços importantes para as micro e pequenas empresas 2017-2018. Rio de Janeiro: Confederação Nacional do Comércio de Bens, Serviços e Turismo, 2017. Disponível em:

http://cnc.org.br/sites/default/files/arquivos/mpe_-_avancos_importantes_2017-

2018.pdf. Acesso em: 25 mar. 2019.

FERREIRA, Calebe da Costa et al. Gestão de capital de giro: contribuição para as micro e pequenas empresas no Brasil. RAP, Rio de Janeiro, 2011. Disponível em: http://bibliotecadigital.fgv.br/ojs/index.php/rap/article/view/7018/5577. Acesso em: 20 abr. 2019.

FRANCISCHINI, Paulino G.; GURGEL, Floriano do Amaral. Administração de materiais e do patrimônio. São Paulo: Thomson Pioneira, 2002.

GIL, A. C. Como elaborar projetos de pesquisa. 4. ed. São Paulo: Atlas, 2007.

KOTLER, P. Administração de marketing. São Paulo: Prentice Hall, 1998.

LETTI, G. C.; GOMES, L. C. Curva ABC: melhorando o gerenciamento de estoques de produtos acabados para pequenas empresas distribuidoras de alimentos.

Update-Revista de Gestão de Negócios, v. 1, n. 2, p. 66-86, 2014.

LUSTOSA, et al. Planejamento e controle da produção. Rio de Janeiro: Elsevier, 2008.

LOPRETE, Diego et al. Gestão de estoque e a importância da Curva ABC. Lins, 2009. Disponível em:

http://www.unisalesiano.edu.br/encontro2009/trabalho/aceitos/CC35509178809.pdf. Acesso em: 20 abr. 2019.

LUCHEZZI, Celso. Gestão de armazenamento, estoque e distribuição - GAED. São Paulo: Pearson Education do Brasil, 2015. 


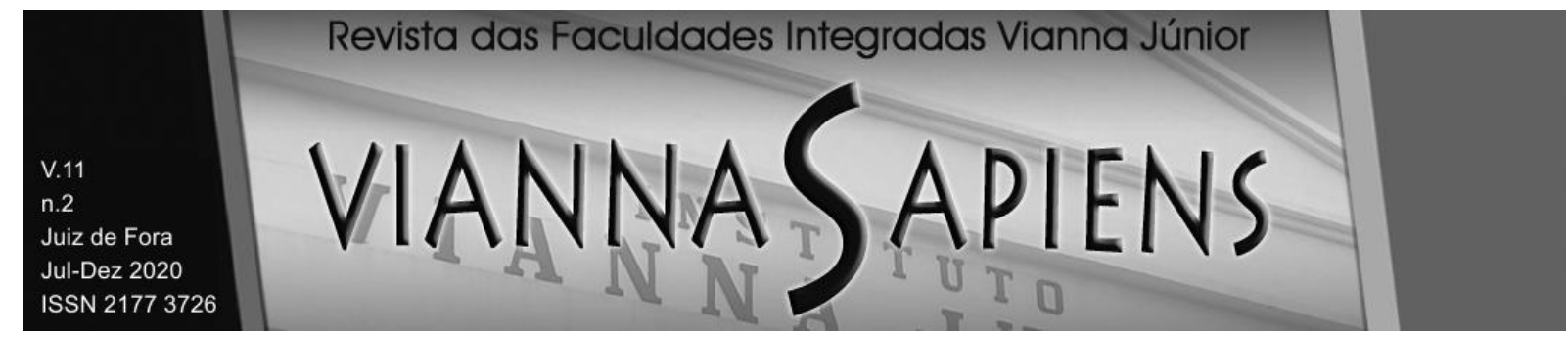

MONKS, G. Joseph. Administração da produção. São Paulo: Editora Mc Graw-Hill, 1987.

MORAES, Giseli D. de Almeida. Tecnologia da informação na pequena empresa: Uma estratégia sobre sua contribuição à gestão estratégica da informação em empreendimentos industriais dos minidistritos de São José do Rio Preto - SP, 2005. Dissertação (mestrado) - USP, São Paulo, 2005.

MOREIRA, D. A. Administração da produção e operações. 2. ed. São Paulo: Thomson, 2002.

PEINADO, Jurandir; GRAEML, Alexandre R. Administração da produção: operações industriais e de serviços. Curitiba: UnicenP, 2007.

PINTO, C. V. Organização e gestão da manutenção. 2. ed. Lisboa: Edições Monitor, 2002.

PLOSSL, G. W. Production and Inventory Control. 2nd ed. Englewood Cliffs, New Jersey: Prentice Hall, 1985.

POZO, Hamilton. Administração de recursos materiais e patrimoniais: uma abordagem logística. 6. ed. São Paulo: Atlas, 2010.

PRODANOV, Cleber Cristiano; FREITAS, Ernani Cesar de. Metodologia do trabalho científico: métodos e técnicas da pesquisa e do trabalho acadêmico. 2. ed. Novo Hamburgo: Feevale, 2013. Disponível em:

http://www.feevale.br/Comum/midias/8807f05a-14d0-4d5b-b1ad-1538f3aef538/Ebook\%20Metodologia\%20do\%20Trabalho\%20Cientifico.pdf. Acesso em: 10 maio 2019.

RICHARDSON, Roberto Jarry. Pesquisa social: métodos e técnicas. 3. ed. São Paulo: Atlas, 1999.

SAMANEZ, C. P. Engenharia econômica. São Paulo: Pearson Prentice Hall, 2009. 


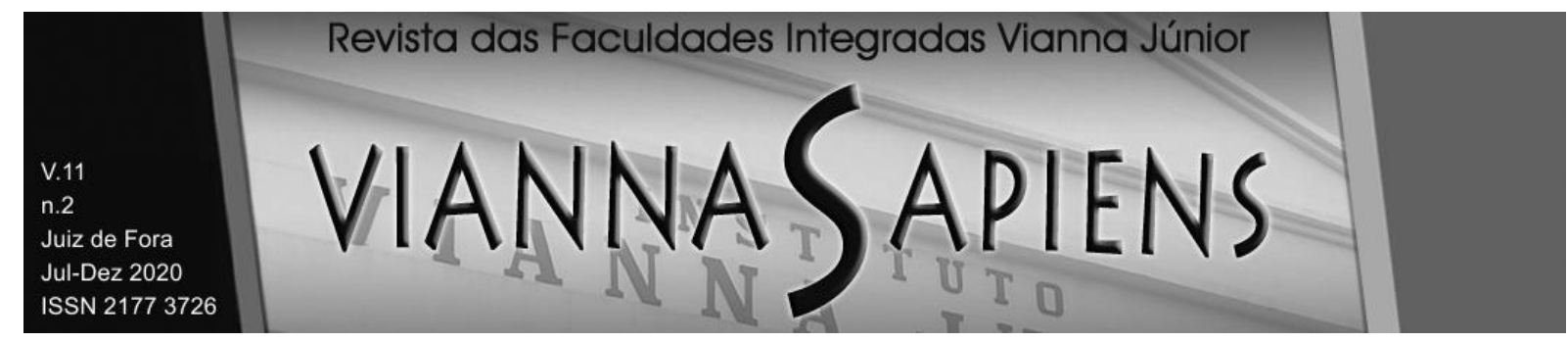

SANTANA, Silvio Leonardo Tulio. Gestão de Estoque: um estudo de caso numa indústria alimentícia. Monografia de especialização (Especialização em Engenharia de Produção) - Universidade Tecnológica Federal do Paraná. Ponta Grossa, 2014. Disponível em:

http://repositorio.roca.utfpr.edu.br/jspui/bitstream/1/5913/1/PG_CEEP_2014_1_24.pd f. Acesso em: 28 abr. 2019.

SEBRAE. Como montar uma mercearia. 2000. Disponível em: http://www.sebrae.com.br/sites/PortalSebrae/ideias/como-montar-umamercearia,0d187a51b9105410VgnVCM1000003b74010aRCRD. Acesso em: 15 abr. 2019.

SEBRAE: Sobrevivência das empresas. 2016. Disponível em: https://datasebrae.com.br/sobrevivencia-das-empresas/. Acesso em: 24 abr. 2019.

SEBRAE. Anuário do trabalho nos pequenos negócios: 2015. 8.ed. Brasília, DF: DIEESE, 2017. Disponível em:

https://www.dieese.org.br/anuario/2017/anuarioDosTrabalhadoresPequenosNegocio s.pdf. Acesso em: 17 mar. 2019.

SEBRAE: Perfil das microempresas e empresas de pequeno porte. 2018.

Disponível em:

http://www.sebrae.com.br/Sebrae/Portal\%20Sebrae/UFs/RO/Anexos/Perfil\%20das\% 20ME\%20e\%20EPP\%20-\%2004\%202018.pdf. Acesso em: 28 abr. 2019.

SILVA, Renaud B. Administração de material: teoria e prática. Rio de Janeiro: Associação Brasileira de Administração de Material, 1981. v.l.

SILVEIRA, Denise Tolfo; CÓRDOVA, Fernanda Peixoto. A pesquisa científica. 2012. Disponível em:

http://www.cesadufs.com.br/ORBI/public/uploadCatalago/09520520042012Pratica_d e_Pesquisa_I_Aula_2.pdf. Acesso em: 20 abr. 2019.

SLACK, Nigel; et al. Administração da produção. 3. ed. São Paulo: Editora Atlas, 2009. 


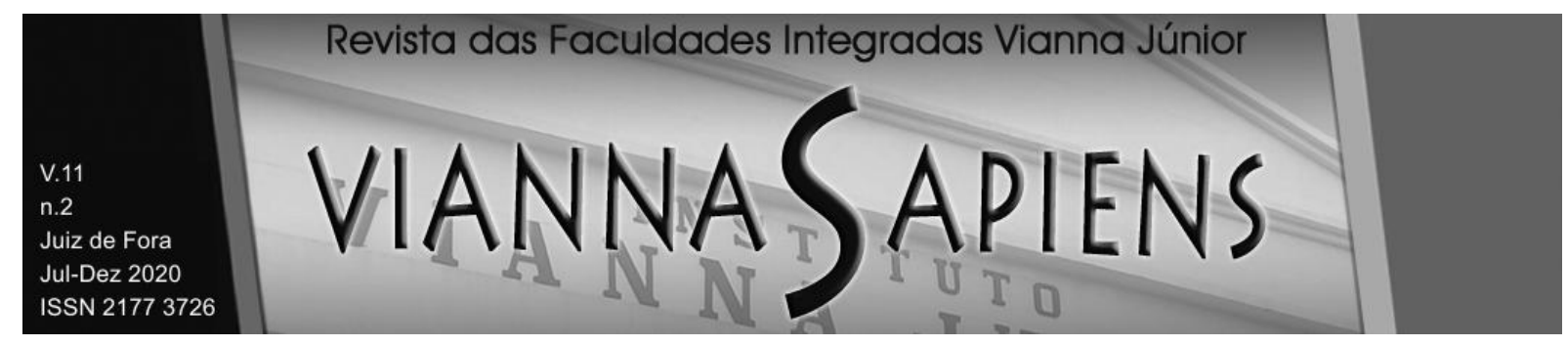

TADEU, Hugo Ferreira Braga. Gestão de estoques: fundamentos, modelos matemáticos e melhores práticas aplicadas. 1. ed. São Paulo: CENGAGE, 2010.

THIOLLENT, Michael J. M. Metodologia da pesquisa-ação. 3. ed. São Paulo: Cortez; Autores Associados, 1986.

TÓFOLI, I. Administração financeira empresarial. São José do Rio Preto: Raízes, 2012.

TUBINO, Dalvio Ferrari. Planejamento e controle da produção: teoria e prática. 2. Ed. São Paulo: Atlas, 2009.

VENANZI, Délvio; SILVA, Orlando Roque da. Gerenciamento da produção e operações. 1. Ed. Rio de Janeiro: LTC, 2013.

ZIMMERER, T. W; SCARBOROUGH, N. M. Essentials of small business management. New York: Macmillan college, 1994.

Recebido em 13/04/2020

Publicado em 31/08/2020 